\title{
Proteomic Analysis Demonstrates a Molecular Dialog Between Trichoderma guizhouense NJAU 4742 and Cucumber (Cucumis sativus L.) Roots: Role in Promoting Plant Growth
}

\author{
Qiumei Liu, Siyu Tang, Xiaohui Meng, Han Zhu, Yiyong Zhu, Dongyang Liu, ${ }^{\dagger}$ and Qirong Shen \\ Jiangsu Provincial Key Lab of Solid Organic Waste Utilization, Jiangsu Collaborative Innovation Center of Solid Organic \\ Wastes, Educational Ministry Engineering Center of Resource-saving fertilizers, Nanjing Agricultural University, Nanjing \\ 210095, Jiangsu, Peoples Republic of China
}

Accepted 20 January 2021.

\begin{abstract}
Trichoderma is a genus of filamentous fungi that play notable roles in stimulating plant growth after colonizing the root surface. However, the key proteins and molecular mechanisms governing this stimulation have not been completely elucidated. In this study, Trichoderma guizhouense NJAU 4742 was investigated in a hydroponic culture system after interacting with cucumber roots. The total proteins of the fungus were characterized, and the key metabolic pathways along with related genes were analyzed through proteomic and transcriptomic analyses. The roles played by the regulated proteins during the interaction between plants and NJAU 4742 were further examined. The intracellular or extracellular proteins from NJAU $\mathbf{4 7 4 2}$ and extracellular proteins from cucumber were quantified, and the high-abundance proteins were determined which were primarily involved in the shikimate pathway (tryptophan, tyrosine, and phenylalanine metabolism, auxin biosynthesis, and secondary metabolite synthesis). Moreover, ${ }^{15} \mathrm{~N}-\mathrm{KNO}_{3}$ labeling analysis indicated that NJAU 4742 had a strong ability to convert nitrogenous amino acids, nitrate, nitrile, and amines into ammonia. The auxin synthesis and ammonification metabolism pathways of NJAU 4742 significantly contributed to plant growth. The results of this study demonstrated the crucial metabolic pathways involved in the interactions between Trichoderma spp. and plants.
\end{abstract}

Keywords: ammonification, auxin synthesis, fungal effectors, fungus-plant interactions, genomics, metabolomics, promotion mechanism, proteome, Trichoderma guizhouense NJAU 4742

${ }^{\dagger}$ Corresponding author: D. Liu: liudongyang@njau.edu.cn

Funding: This research was financially supported by the National Key Research and Development Program of China (2017YFD0200806), the Independent Innovation Fund Project of Agricultural Science and Technology in Jiangsu Province (grant number CX (18)1005), the 111 Project (B12009), and the Chinese Science and Technology Ministry (973 Program, 2015CB100506).

*The e-Xtra logo stands for "electronic extra" and indicates that a supplementary file, supplementary tables, and supplementary materials are published online.

The author(s) declare no conflict of interest.

(c) (1) (-) $\odot$ Copyright $\odot 2021$ The Author(s). This is an open access article cc) 1 (1)
Trichoderma spp. make up a group of cosmopolitan soil fungi that are beneficial to agricultural activities. These fungi can act as biofungicides, remediate soils being contaminated with metals or chemical wastes, or even elicit plant defense after interacting closely with the surroundings (Meena and Swapnil 2019; Sharma et al. 2019). Numerous researchers have observed that Trichoderma fungi can colonize plant roots, promote plant growth, enhance nutrient availability, and increase crop productivity by competing with other microorganisms, releasing nutrients, modifying the rhizosphere, producing antibiotics, and secreting cell-wall-degrading enzymes (Gupta and Bar 2020; Viterbo et al. 2010). Importantly, these functions help to mediate the molecular interactions between plants and microorganisms. Meanwhile, all of these beneficial associations require mutual recognition and substantial coordination of plant and microbial responses.

For plant-growth-promoting rhizobacteria, it was demonstrated that the secreted proteins were central to the bacteria-host interaction (Sayyed et al. 2019). Similarly, changes in secreted proteins from filamentous fungi might affect fungus-plant molecular interactions after association with plant roots. Small secreted proteins (SSPs) secreted by fungi always have fewer than 300 amino acids, secretion signal peptides, and cysteinerich subgroups (Kim et al. 2016). The proportion of SSPs was observed to range from 40 to $60 \%$ of the secretomes across all lifestyles and phylogenetic groups within the fungal kingdom. SSPs can suppress host defense responses, as well as modulate their physiology (Feldman et al. 2020). Fungal secretomes are primarily composed of several protein categories, including proteases, lipases, and carbohydrate-active enzymes (CAZymes). Among the secretomes of Trichoderma spp., CAZymes might facilitate penetration and colonization by surmounting the first barrier by partially digesting the cell wall (Mendoza-Mendoza et al. 2018). Chitinase participates in the catalytic decomposition of chitin from the phytopathogenic fungal cell wall and releases chitooligosaccharides that have mitogenic and morphogenic effects such as cytokines and inhibitors of auxin transport. Therefore, these products indirectly contribute to increasing root formation and stimulating plant defense against phytopathogenic fungi (Hermosa et al. 2013). Cheng et al. (2018) found that small (Sm1) protein and eliciting plant response-like (Epl1) protein could serve as microbial or microbial-associated molecular patterns to stimulate plant immunity in cotton and maize. Moreover, molecular recognition involved in plant-microbe interaction depends on phytohormone communication. The high 
level of 1-aminocyclopropane-1-carboxylate deaminase (ACCD) was observed to induce considerable growth promotion in tomato, which might prevent acceleration of the transformation of ethylene degradation of indole-3-acetic acid (IAA) by rhizosphere microorganisms (Vejan et al. 2016). In addition, the production of microbial phytohormone, including auxins, cytokines, gibberellins, abscisic acid, and ethylene, is also very important for improving plant physiology, regulating root architecture, and promoting plant growth (Spaepen 2015).

Studies in the past few decades have contributed to our understanding of the detailed molecular mechanisms of the communication between plants and microbes. The metabolic results of this communication, however, are only beginning to be investigated. Analysis of the proteome will provide new insight. In this study, we characterized the proteome of the biocontrol strain Trichoderma guizhouense NJAU 4742 interacting with cucumber in a hydroponic system.

\section{RESULTS}

\section{Growth promotion effect of the NJAU 4742 strain on cucumber.}

Coculture of the NJAU 4742 strain for 25 days with cucumber in a hydroponic system was applied to assess the growth promotion effect (Fig. 1). After cocultivation for 25 days in a 250-ml triangular flask containing $100 \mathrm{ml}$ of half-strength Murashige and Skoog (MS) (Murashige and Skoog 1962) medium, a significant growth promotion effect on cucumber seedlings was observed in the cucumber roots grown with NJAU 4742 in $0.2 \times$ MS medium (TC) treatment compared with the cucumber grown without NJAU 4742 under the same conditions (C) treatment (Fig. 1A). The growth index of cucumber seedlings in the TC and NJAU 4742 grown without cucumber under the same conditions $(\mathrm{T})$ treatments was also evaluated, including shoot biomass and root biomass production (Fig. 1B). The results indicated that the plant height, plant diameter, aboveground biomass, and leaf area of cucumber seedlings in the TC treatment increased by $13.5,19.1,35.5$, and $57.4 \%$, respectively, compared with those in the $\mathrm{C}$ treatment, which demonstrated that NJAU 4742 had a considerable ability to promote plant growth. In particular, the number of lateral root tips in the TC treatment increased by $64.7 \%$ compared with that observed in the $\mathrm{C}$ treatment. Additionally, the root activity (tetrazolium chloride [TTC]) at $243.7 \mu \mathrm{g}$ per gram of fresh weight per hour) in the TC treatment was higher than that in the $\mathrm{C}$ treatment (TTC at $95.6 \mu \mathrm{g}$ per gram of fresh weight per hour) (Fig. 1C). All of the results described above suggested that the inoculation of NJAU 4742 could significantly increase the growth of cucumber seedlings, probably due to the presence of various compositions that were essential for increasing plant biomass and regulating root morphology.

\section{Proteomic data quality control and quantification of the proteins.}

In this study, proteomic analysis was employed to demonstrate how NJAU 4742 promoted plant growth and how plants responded to the presence of this fungus. Intracellular protein samples were extracted from the coculture system containing NJAU 4742 and cucumber roots (TCI) and pure cultured NJAU 4742 without cucumber roots (TI) under the same conditions. Also, extracellular proteins were extracted from the coculture system containing NJAU 4742 and cucumber roots (TCE) and pure cultured NJAU 4742 without cucumber roots (TE) under the same conditions. These proteins-TCI, TI, TCE, TE, and pure cultured cucumber (CE) - from various treatments were analyzed by sodium dodecyl sulfate polyacrylamide gel electrophoresis (SDS-PAGE). The results indicated that there were no distinct differences between the TCI and TI lanes, which indicated that the effect of microbe-plant interactions on the intracellular protein in NJAU 4742 was not significant (Fig. 2A). The SDS-PAGE results showed that extracellular proteins from the
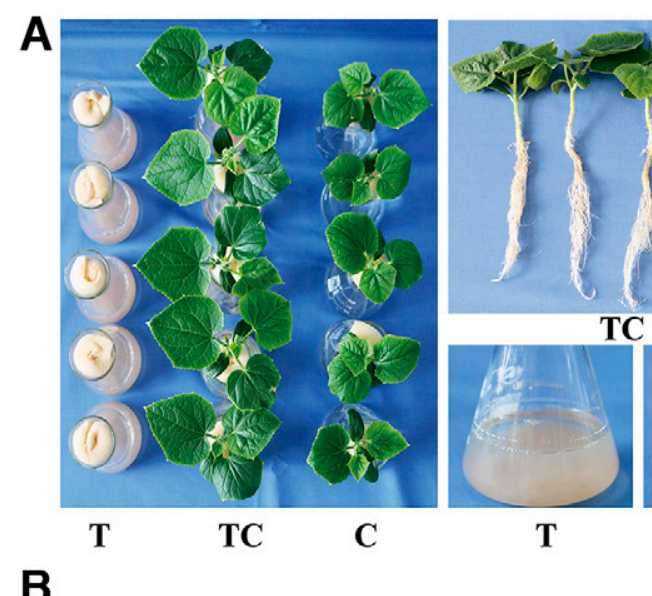

$\mathbf{T}$

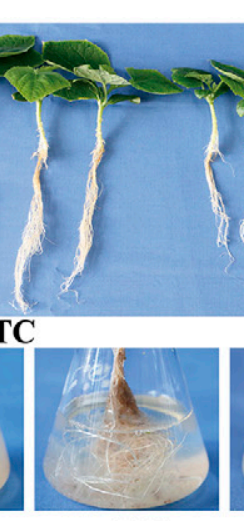

TC

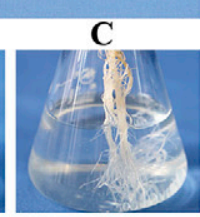

C

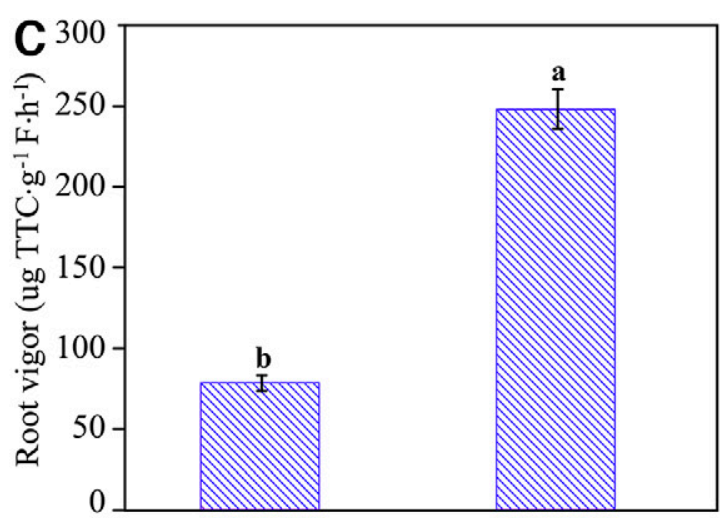

C

TC

Cucumber seedlings physiological index

\begin{tabular}{|c|c|c|c|c|c|c|c|c|c|}
\hline Treatment & Shoot length $S$ & Shoot diameter & SPDA & Leaf area & $\mathrm{SW}(\mathrm{F})^{*}$ & Root length* & $\mathrm{RW}(\mathrm{F})^{*}$ & Surface area $\left(\mathrm{cm}^{-1}\right)^{*}$ & Root tips* \\
\hline $\mathrm{C}$ & $11.77 \pm 0.86 \mathrm{~b}$ & $2.36 \pm 0.19 b$ & $38.49 \pm 1.29 b$ & $22.4 \pm 1.25 b$ & $1.80 \pm 0.26 \mathrm{~b}$ & $11.34 \pm 1.53 b$ & $0.42 \pm 0.07 \mathrm{~b}$ & $0.47 \pm 0.06 \mathrm{~b}$ & $541 \pm 76.1 \mathrm{~b}$ \\
\hline $\mathrm{TC}$ & $13.36 \pm 0.87 \mathrm{a}$ & $2.81 \pm 0.06 \mathrm{a}$ & $41.39 \pm 1.59 \mathrm{a}$ & $35.5 \pm 0.33 \mathrm{a}$ & $2.44 \pm 0.23 \mathrm{a}$ & $19.47 \pm 1.98 \mathrm{a}$ & $0.67 \pm 0.14 \mathrm{a}$ & $0.63 \pm 0.03 \mathrm{a}$ & $891 \pm 57.4 \mathrm{a}$ \\
\hline
\end{tabular}

Fig. 1. Effects of strain NJAU 4742 inoculation on the growth of cucumber roots. A, Growth condition of strain NJAU 4742 and cucumber seedlings in the hydroponic system. $\mathrm{T}=$ the pure culture of strain NJAU $4742, \mathrm{TC}=$ the cultural system of cucumber inoculated with strain $\mathrm{NJAU} 4742$, and $\mathrm{C}=$ the individual culture system for cucumber seedlings. B, Growth index of cucumber seedlings, including shoot length, shoot diameter, soil plant analysis development value (SPDA), leaf area, fresh shoot weight $[\mathrm{SW}(\mathrm{F})]$, root length, fresh root weight $[\mathrm{RW}(\mathrm{F})]$, surface area (in square centimeters), and root tips after 25 days. C, Root vigor of cucumber roots in different treatments after 25 days of cultivation. Bars indicate the standard error of five replicates and an asterisk (*) indicates significance at $P<0.005$. 
same treatment had good repeatability, and significant differences were observed among TCE, TE, and CE (Fig. 2D). Both the band diversity and intensity in TCE were more extensive than those in $\mathrm{CE}$ and $\mathrm{TE}$, which also demonstrated that microbe-plant interactions might increase the secretomes of NJAU 4742 and cucumber. After preanalysis by SDS-PAGE, liquid chromatography tandem mass spectrometry (LC-MS/MS) data quality control was also performed, because this step might be considered one of the critical parameters for quantitative proteomic analysis. The results showed that the abundances in all samples (TCI/TI, TCE/CE, and TCE/TE) conformed to a normal distribution (Fig. 2B and E), indicating that most of the proteins were authentically detected squared. Moreover, Pearson correlation analysis was applied to reveal the relationship among different treatments, and the repeatability of different biological replicates was described by the value of $R^{2}$. In this instance, high-correlation $R^{2}$ values $\left(0.78<R^{2}<\right.$ $0.97)$ were obtained in all biological replicates, which indicated that high-quality LC-MS/MS data were obtained in this study (Fig. 2C and F).

In total, 1,059 intracellular proteins were identified in the whole-cell lysates obtained from NJAU 4742 mycelium. The quantitative analysis results indicated that 510 proteins (48.2\%) exhibited significant differences (fold-change $>2$ or fold-change $<0.5, P$ value $<0.05)$ between TCI and TI treatments; among these proteins, 247 were upregulated and 263 were downregulated in the TCI treatment (Supplementary
Dataset S1). The secretomes from NJAU 4742 and cucumber roots were also quantified, and the results indicated that 62 proteins were identified in both the TCE and TE samples. In all, 24 proteins $(38.7 \%)$ in TCE exhibited significant differences from those in the TE treatments, with 18 being upregulated and 4 being downregulated (Supplementary Dataset S2). In contrast, fewer secreted proteins from cucumber were identified and quantified; in total, 36 proteins were identified in both the TCE and CE samples, including 4 upregulated and 7 downregulated proteins (TCE/CE) (Supplementary Dataset S3). These data concerning the identified proteins enabled in-depth analysis of the responses during the plant-microbe interaction process to be performed.

\section{Proteomic analysis of the total NJAU 4742 proteins and the secreted cucumber root proteins.}

Differentially expressed proteins were annotated by using the Gene Ontology (GO) classification database to further characterize their locations, functions, and processes (Supplementary Fig. $\mathrm{S} 1)$. In total, 1,059 intracellular proteins were identified, and most of them were classified as being involved in catalytic $(42.8 \%)$ and cellular metabolic $(46.74 \%)$ processes. In addition, 48 extracellular proteins from NJAU 4742 were determined to primarily belong to catalytic activity $(43.18 \%)$ and cellular metabolic process $(44.56 \%)$. Moreover, 36 extracellular proteins secreted by cucumber roots were identified as participating in catalytic activity (41.18\%) and antioxidant activity $(8.25 \%)$
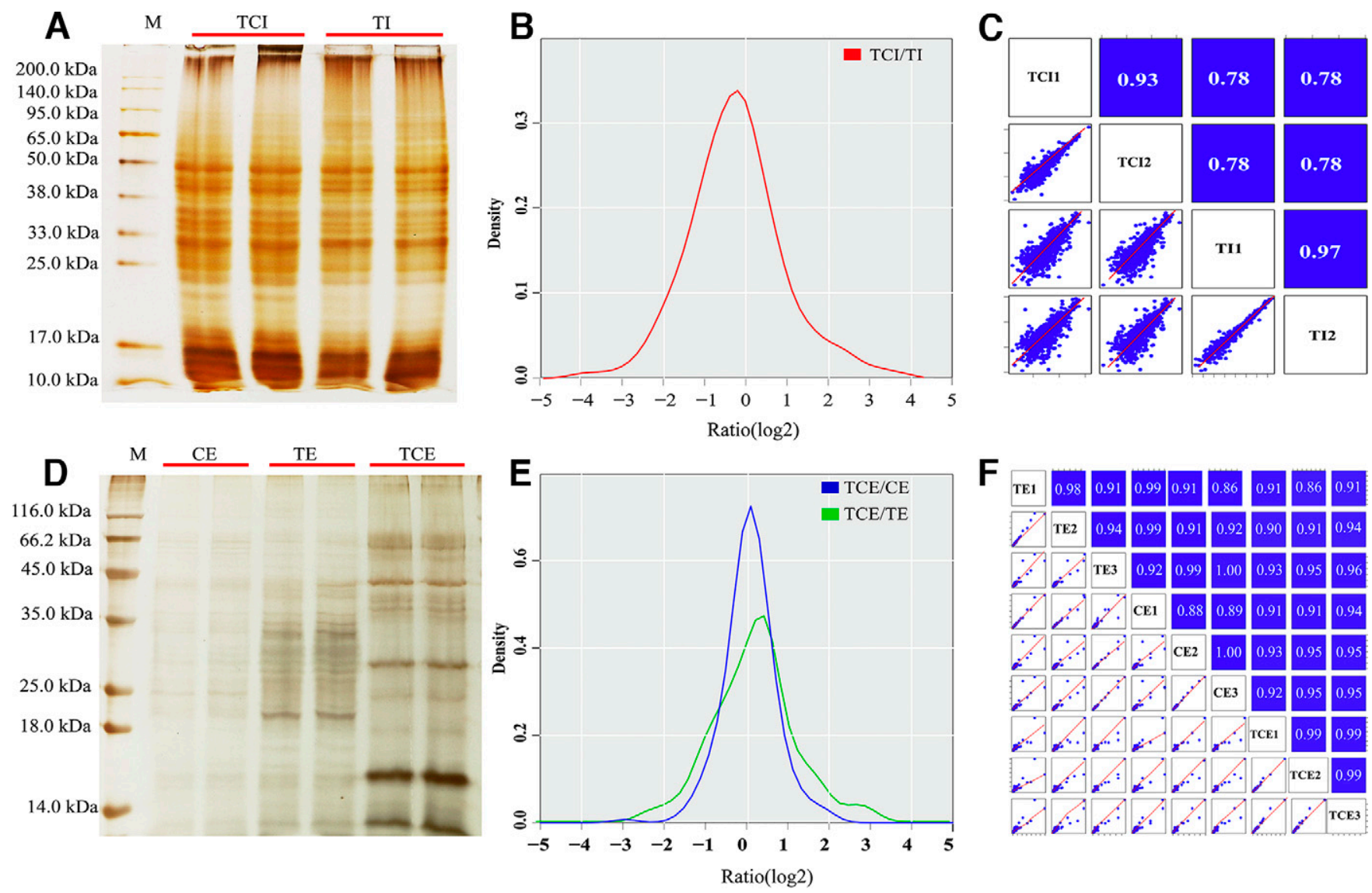

Fig. 2. Sodium dodecyl sulfate polyacrylamide gel electrophoresis (SDS-PAGE) and liquid chromatography tandem mass spectrometry data qualification of strain NJAU 4742 total proteins and cucumber extracellular proteins in different treatments. A, SDS-PAGE analysis of the different treatments. M = the standard protein marker, TCI $=$ the intercellular proteins extracted from strain NJAU 4742 in the NJAU 4742-cucumber interaction system, and TI = the intercellular proteins of strain NJAU 4742 in the pure cultured system. B, Distribution of the intracellular protein abundances in the TCI versus TI treatment. C, Correlation analysis of intracellular proteins the TCI versus TI treatment. D, SDS-PAGE analysis of extracellular proteins extracted from the coculture system containing NJAU 4742 and cucumber roots (TCE) versus pure cultured NJAU 4742 without cucumber roots (TE) and TCE versus pure cultured cucumber (CE). E, Distribution of the extracellular protein abundances in the TCE versus TE and CE versus CE treatments. F, Correlation analysis of extracellular proteins in the TCE versus TE and TCE versus CE treatments. 
pathways. These results indicated that the identified proteins were primarily involved in different biological processes, which influenced the responses of Trichoderma spp. and plants to construct a positive molecular dialog.

After GO analysis, the data were filtered for a $1 \%$ false discovery rate (FDR), and the protein abundance ratios were calculated. Furthermore, statistical parameters $(P$ values, coefficient of variation values, fold change, and protein abundances) were also employed to select the expression of differential proteins at the peptide and protein levels. Hierarchical clustering of significantly different intracellular and extracellular proteins obtained from NJAU 4742 showed some more abundant and specifically accumulated proteins in TCI (Fig. 3). The analysis of intracellular protein samples from TCI and TI performed by using sequential window acquisition of all of theoretical fragment ions (SWATH) quantitation indicated excellent separation of two major distinct clusters corresponding to the culture conditions, in which 263 proteins were upregulated, while the other 247 proteins were downregulated (TCI/TI) (Fig. 3A). Notably, 109 proteins in cluster I involved in metabolic pathways, biosynthesis of secondary metabolites, and some basic metabolic pathways were significantly upregulated in TCI compared with TI. Cluster II showed that 67 proteins involved in ribosome and amino acid metabolism were downregulated in TCI compared with TI, while another 99 proteins primarily involved in the biosynthesis of secondary metabolites were upregulated in cluster III. Most of the proteins involved in the biosynthesis of secondary metabolites (cluster IV) or proteasomes (cluster V) were expressed at low levels in the TCI or TI treatment compared with the TC condition.

The extracellular proteins in all treatments were also analyzed, and the results indicated that the proteins involved in the pathways of starch and sucrose metabolism $(n=13)$, biosynthesis of secondary metabolites $(n=5)$, and peroxisome- and cellwall-degrading enzymes $(n=13)$ were significantly upregulated in NJAU4742 after interacting with cucumber roots (Fig. 3B). Notably, the secretomes from cucumber were associated with the biosynthesis of secondary metabolites and peroxisomes after interacting with NJAU 4742 (Fig. 3C), which also supported the hypothesis that the NJAU 4742 strain could activate the biosynthesis of secondary metabolites in plant roots, thereby promoting plant growth.
Kyoto Encyclopedia of Genes and Genome pathway analysis.

To further characterize the roles of the significantly different proteins in metabolic regulatory processes, Kyoto Encyclopedia of Genes and Genome (KEGG) analysis was performed in this study (Fig. 4). In total, 779 intracellular proteins were annotated by the KEGG database, and they were divided into different metabolic pathways. Based on the results of the KEGG analysis, protein-protein interactions (PPIs) were evaluated by constructing protein networks with Cytoscape (Fig. 4A). All annotated proteins were categorized into 104 categories, and $92 \%$ of these proteins were linked and formed a large interaction network. The results of the PPI analysis showed that these categories, including amino acid metabolism, the oxidative phosphorylation pathway (6.29\%), pyruvate metabolism (5.39\%), glycolysis/gluconeogenesis metabolism (5.13\%), glycolysis/gluconeogenesis metabolism $(5.13 \%)$, citrate cycle (tricarboxylic acid [TCA] cycle) $(3.47 \%)$, energy production, ribosome metabolism $(7.32 \%)$, RNA transport (3.59\%), proteasome metabolism (3.59\%), oxidoreduction, and the biosynthesis of secondary metabolites pathway $(18.36 \%)$, were upregulated in TCI compared with TI. In particular, tryptophan (Trp) metabolism (3.85\%), arginine metabolism $(2.82 \%)$, glutamate metabolism $(2.44 \%)$, tyrosine metabolism $(3.34 \%)$, nitrogen metabolism $(1.41 \%)$, phenylalanine metabolism (2.18\%), and the biosynthesis of other amino acids were significantly affected after interaction with cucumber roots, which demonstrated that these pathways may be related to plant growth promotion in the NJAU 4742 strain. In addition, 57 ribosomal subunit proteins containing $50 \mathrm{~S}$ and $30 \mathrm{~S}$ ribosomal subunit complexes were determined to be highly enriched in the ribosome pathway $(P$ value $=2.3 \mathrm{e}-23$ ); among these proteins, most were upregulated and accelerated the entire metabolism of the NJAU 4742 strain. KEGG enrichment analysis for extracellular proteins of the NJAU 4742 strain and cucumber roots was also performed, and the 20 most critical enriched pathways were presented. All of the annotated extracellular proteins from NJAU 4742 were categorized into 38 categories, primarily starch and sucrose metabolism (10.29\%), biosynthesis of secondary metabolites (10.29\%), amino sugar and nucleotide sugar metabolism $(7.35 \%)$, peroxisome $(2.94 \%)$, Trp metabolism (2.94\%), and phenylalanine metabolism $(2.94 \%)$, in which Trp metabolism, phenylalanine metabolism, and starch and sucrose metabolism were significantly overexpressed in TCE compared
A

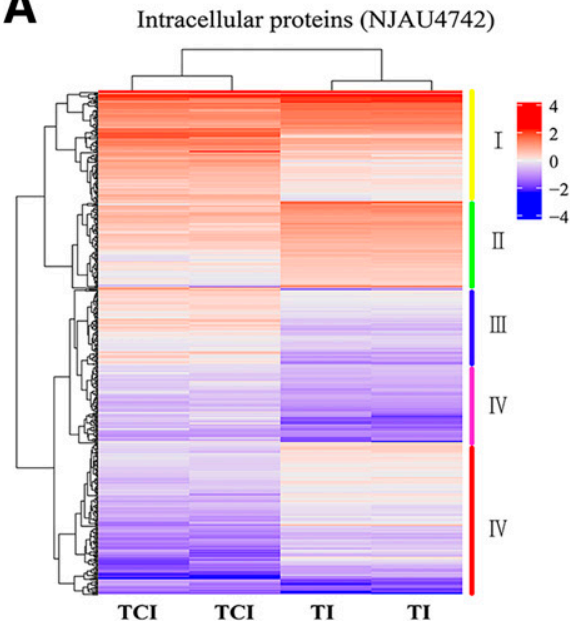

B

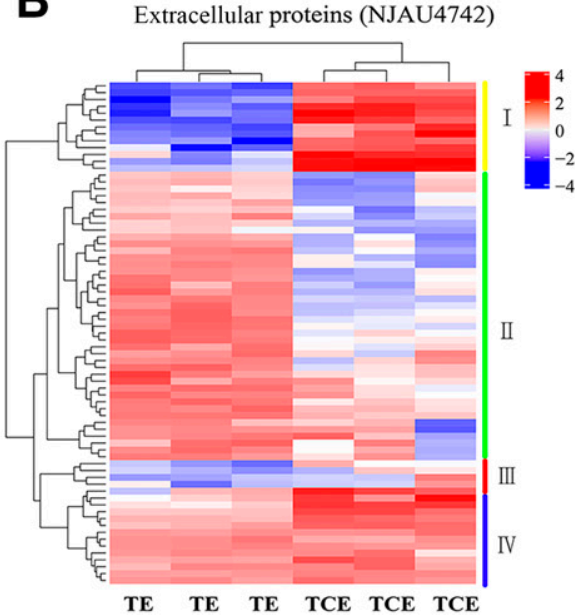

C Extracellular proteins (cucumber)

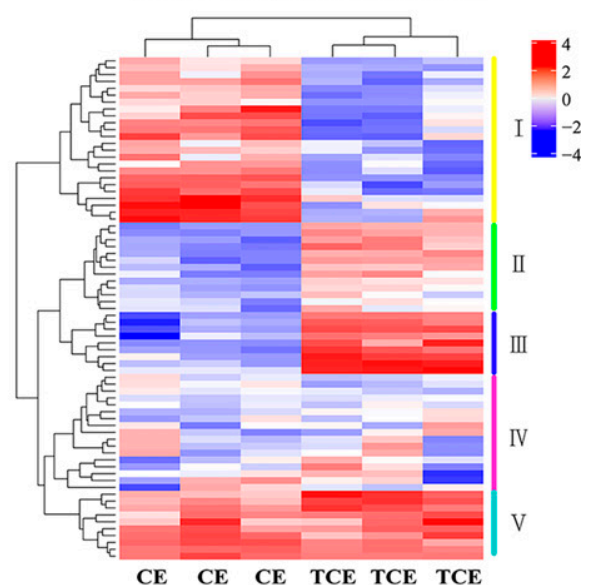

Fig. 3. Hierarchical cluster analysis of the identified total proteins from strain NJAU 4742 and extracellular proteins of cucumber roots in different treatments. A, Hierarchical cluster analysis of the identified intracellular proteins extracted from the coculture system containing NJAU 4742 and cucumber roots (TCI) and pure cultured NJAU 4742 without cucumber roots (TI). B, Hierarchical cluster analysis of the identified extracellular proteins from pure cultured NJAU 4742 without cucumber roots (TE) and the coculture system containing NJAU 4742 and cucumber roots (TCE). C, Hierarchical cluster analysis of the identified extracellular proteins from pure cultured cucumber (CE) and TCE. 
with TE (Fig. 4B). Meanwhile, all of the annotated extracellular proteins from cucumber roots were categorized into 26 categories, primarily including biosynthesis of secondary metabolites (42.86\%), phenylalanine metabolism (23.81\%), amino sugar and nucleotide sugar metabolism $(9.52 \%)$, plant-pathogen interaction $(9.52 \%)$, peroxisome $(4.76 \%)$, starch and sucrose metabolism (4.76\%), the Trp metabolism pathways $(3.62 \%)$, the tyrosine metabolism pathways $(2.84 \%)$, and cyanoamino acid metabolism $(2.38 \%)$, in which the Trp metabolism pathways, tyrosine metabolism pathways, and starch and sucrose metabolism pathways were significantly overexpressed in TCE compared with those in CE (Fig. 4C).

In this study, in total, 56 intracellular proteins from NJAU 4742 were obtained during the interaction between Trichoderma spp. and plants, and they were determined to be involved in cell wall degradation and the synthesis of secondary metabolites (Table 1). Additionally, the extracellular proteins from the NJAU 4742 strain and cucumber in different treatments were also quantified (Table 1), and the results showed that nine upregulated proteins, including 1,3- $\beta$-glucosidase, the glycosyl hydrolase $(\mathrm{GH})$ family, expansion-like proteins, and peroxidase, were related to phenylalanine metabolites, while another six upregulated proteins were related to peroxidases. A low content of the expansion-domain protein (A1A105468.1) was obtained in TE, and the content of this protein increased dramatically in TCE (Supplementary Dataset S2). Three GH family proteins (A1A107070.1, A1A107404.1, and A1A101886.1) were strongly secreted by the NJAU 4742 strain in TCE, whereas they were not observed in TE. In addition, two peroxidases (A1A111042.1 and A1A111046.1) observed at higher abundance in TCE than in TE might play important roles in plant-microorganism interactions. Overall, these findings indicated that the proteins from NJAU 4742 and cucumber involved in different biological processes could influence the interaction process between plants and microorganisms.

\section{Secondary metabolite-associated proteins related} to auxin biosynthesis and nitrogen metabolism pathways.

As in the auxin precursor synthesis pathway, the shikimate pathway was observed to play a critical role in regulating secondary metabolism, and the proteins involved in this pathway were also selected to clarify their functions (Supplementary
Dataset S4). Based on the KEGG analysis results, 71 intracellular proteins related to the shikimate metabolism pathway were significantly up- or downregulated in TCI compared with those in TI (Fig. 5). The shikimate pathway comprises seven reactions catalyzed by six enzymes to produce chorismate. Two phospho-2-dehydro-3-deoxyheptonate aldolases (A1A105819.1 and A1A111349.1) were upregulated in TCI, which accelerated the transformation of phosphoenolpyruvate and erythrose 4-phosphate to form shikimate. Subsequently, shikimate could be hydrolyzed by chorismate synthase (CS) (A1A108794.1), which was increased by 1.55 -fold in TCI compared with TI. The metabolism of chorismate was divided into two branches, and the first branch was the L-phenylalanine biosynthesis pathway, in which one chorismate mutase (A1A110052.1) and two aspartate aminotransferases (A1A107455.1 and A1A109221.1) were upregulated after interacting with cucumber roots. The second branch was related to the L- Trp metabolism pathway, in which four of seven differentially expressed enzymes (A1A103857.1, A1A102940.1, A1A108213.1, and A1A110565.1) were upregulated in TCI. IAA synthesized by microbes plays a critical role during plant-microbe interactions; thus, further research investigating biosynthesis in NJAU 4742 was strongly warranted. The proteomic analysis results showed that six differentially expressed proteins involved in auxin biosynthesis increased in TCI, and two amidase proteins (A1A101473.1 and A1A103233.1) were upregulated by 1.38 - and 1.58 -fold, respectively, compared with those in TI, which resulted in an increase in IAA. In addition, two important enzymes designated nitrilases (A1A107668.1 and A1A101490.1) were significantly upregulated by 9.79- and 2.52-fold, respectively, and played important roles during catalysis of the conversion of 3-indole-acetonitrile into IAA in the final step of auxin biosynthesis. As another category of enzymes involved in auxin biosynthesis, aldehyde dehydrogenases (A1A100829.1 and A1A101682.1), which were responsible for the formation of IAA biosynthesis by catalyzing 3 -indole-pyruvic acid, were observed to increase by 1.73 - and 2.62-fold, respectively.

Aside from the auxin biosynthesis pathway, 12 differential proteins involved in nitrogen metabolism were observed to change significantly, especially in secreting ammonium ions (Fig. 5). Nitronate monooxygenase (NMO), sulfite oxidase (SO), and monodehydroascorbate reductase (MDHAR), which
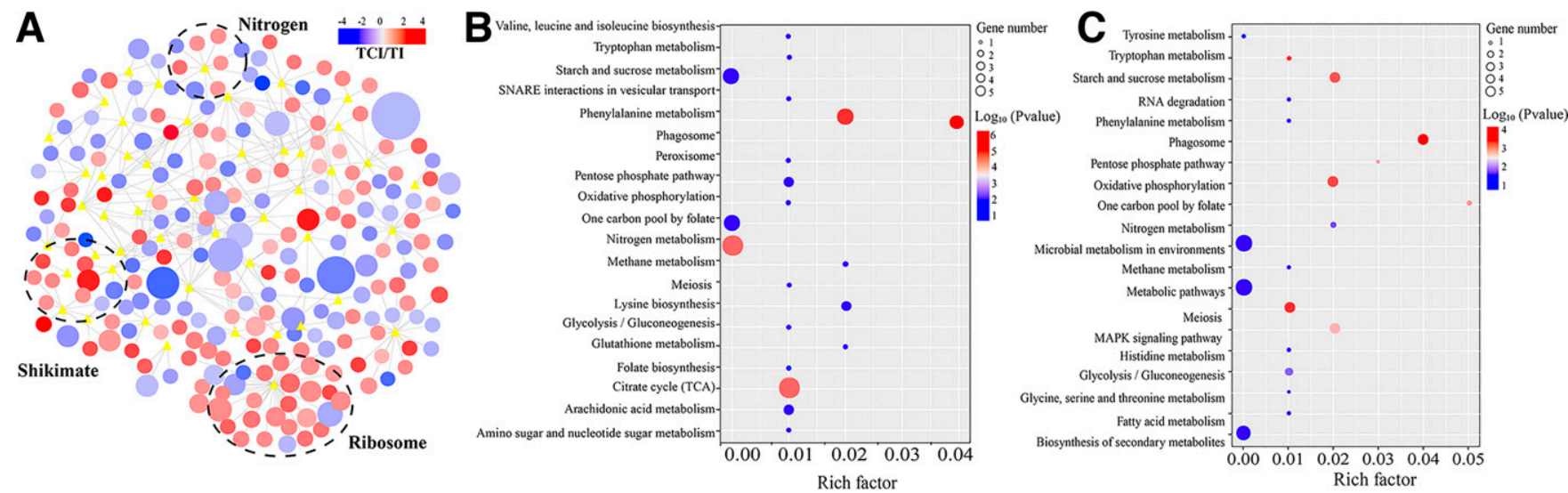

Fig. 4. Protein-protein interaction and Kyoto Encyclopedia of Genes and Genome (KEGG) pathway analysis results of different treatments. A, Proteinprotein interaction analysis results of the intracellular proteins extracted from the coculture system containing NJAU 4742 and cucumber roots (TCI) versus pure cultured NJAU 4742 without cucumber roots (TI) treatments; nodes were annotation proteins (circles) and edges were protein interactions defined by KEGG databases. Protein node sizes indicate the $\log _{10}$ of protein expression values and node colors represented the fold-change (red $=$ upregulated and blue $=$ downregulated). B, KEGG pathway analysis results of the extracellular proteins from strain NJAU 4742 in coculture system containing NJAU 4742 and cucumber roots (TCE) versus pure cultured NJAU 4742 without cucumber (TE) treatment, C, KEGG pathway analysis results of the extracellular proteins from cucumber roots in TCE versus pure cultured cucumber (CE) treatment. Circles indicate the top 20 of the enrichment pathways, and the circle color indicates the expression level of different pathways (red represents upregulation and blue represents downregulation in the form of $\log _{2}$ ), while the circle size indicates the number of different proteins. 
Table 1. Biological function, pathway, and location of differential proteins from Trichoderma guizhouense and cucumber (Cucumis sativus) after 25 days of interaction ${ }^{\mathrm{a}}$

\begin{tabular}{|c|c|c|c|}
\hline $\begin{array}{l}\text { Treatment, } \\
\text { accession number }\end{array}$ & Protein name & PI & $\begin{array}{l}\text { Molecular } \\
\text { size (kDa) }\end{array}$ \\
\hline \multicolumn{4}{|c|}{ Intracellular proteins (T. guizhouense NJAU 4742 with cucumber roots $[\mathrm{TCI}]$ and without cucumber [TI]) } \\
\hline A1A108890.1 & $\beta$-Glucosidase & 5.80 & 94,148 \\
\hline A1A108695.1 & Exochitinase & 5.72 & 64,250 \\
\hline A1A107668.1 & Nitrilase & 5.07 & 34,619 \\
\hline A1A101208.1 & Putative cytochrome P450 oxidoreductase & 5.64 & 36,626 \\
\hline A1A105563.1 & Cytochrome P450 55A1 & 5.49 & 44,221 \\
\hline A1A105566.1 & Lovastatin nonaketide synthase & 6.18 & 195,485 \\
\hline A1A108307.1 & Small GTPase mediated signal transduction & 7.70 & 23,332 \\
\hline A1A108939.1 & Acid trehalase & 6.17 & 116,885 \\
\hline A1A103847.1 & Aldo/keto reductase & 5.72 & 38,583 \\
\hline A1A111753.1 & Core histone $\mathrm{H} 2 \mathrm{~A} / \mathrm{H} 2 \mathrm{~B} / \mathrm{H} 3 / \mathrm{H} 4$ & 10.12 & 14,845 \\
\hline A1A108926.1 & Zinc-binding dehydrogenase & 4.86 & 37,425 \\
\hline \multicolumn{4}{|c|}{ Extracellular (T. guizhouense NJAU 4742 with cucumber roots [TCE] and without cucumber [TE]) } \\
\hline A1A103792.1 & Glucan $1,3-\beta$-glucosidase & 4.84 & 107,129 \\
\hline A1A108471.1 & $\beta$-Glucosidase & 5.10 & 52,950 \\
\hline A1A107070.1 & Glycosyl hydrolases family 16 & 4.86 & 31,448 \\
\hline A1A107404.1 & Glycosyl hydrolase family $18-1$ & 4.57 & 42,108 \\
\hline A1A101886.1 & Glycosyl hydrolase family 18 & 4.74 & 149,586 \\
\hline A1A105468.1 & Expansin-like protein & 5.20 & 13,247 \\
\hline A1A111042.1 & Cytochrome c peroxidase, mitochondrial & 9.14 & 47,104 \\
\hline A1A111046.1 & Cytochrome c peroxidase, mitochondrial & 9.14 & 47,104 \\
\hline A1A107883.1 & Peroxidase; WSC domain & 4.32 & 97,643 \\
\hline A1A112027.1 & Peroxidase activity; response to oxidative stress & 4.70 & 60,831 \\
\hline A1A105229.1 & Replication factor $\mathrm{C}$ subunit 1 & 8.59 & 114,378 \\
\hline A1A102263.1 & GTP binding proteins & 5.05 & 43,245 \\
\hline A1A110737.1 & Heterokaryon incompatibility protein & 6.43 & 152,862 \\
\hline A1A106704.1 & Cysteine-rich secretory protein family (SCCP) & 5.28 & 17,458 \\
\hline A1A101889.1 & LysM domain & 6.47 & 59,827 \\
\hline A1A100181.1 & Prolyl-tRNA synthetase, partial & 6.10 & 63,096 \\
\hline A1A110737.1 & Heterokaryon incompatibility protein & 6.43 & 152,862 \\
\hline \multicolumn{4}{|c|}{ Extracellular proteins (Cucumis sativus, TCE/CE) } \\
\hline XP_004151874.1 & Blue copper protein-like & 4.62 & - \\
\hline XP_004143988.2 & Protein P21-like & 4.49 & - \\
\hline XP_004139239.1 & Pathogenesis-related protein PR-4 & 8.02 & - \\
\hline XP_004151729.2 & Acidic endochitinase & 4.63 & - \\
\hline XP_004149369.1 & Peroxidase P7-like & 8.5 & - \\
\hline XP_011658156.1 & Glucan endo-1,3- $\beta$-glucosidase & 6.47 & - \\
\hline XP_004154012.1 & Peroxidase 7 & 6.19 & - \\
\hline XP_011658861.1 & Basic form of pathogenesis-related protein 1-like & 4.87 & - \\
\hline XP_011654331.1 & Extensin-2-like & 9.54 & - \\
\hline XP_011660113.1 & $\beta$-Glucosidase 12-like & 9.19 & - \\
\hline XP_004142246.1 & Peroxidase 2-like & 9.19 & - \\
\hline XP_011653567.1 & Peroxidase 2-like & 5.86 & - \\
\hline XP_004145227.1 & Endochitinase PR4-like & 4.88 & - \\
\hline
\end{tabular}

(Continued on next page)

${ }^{\mathrm{a}} \mathrm{FC}=$ fold change; $\mathrm{Sig}=$ signal peptide.

${ }^{\mathrm{b}} \mathrm{TRP}=$ tryptophan metabolism, NIT $=$ nitrogen metabolism, PHE $=$ phenylalanine metabolism, GLY $=$ glycolysis or gluconeogenesis, PPI $=$ protein - protein interaction, BSM = biosynthesis of secondary metabolites, $\mathrm{SSM}=$ starch and sucrose metabolism, PEO $=$ peroxisome, MME $=$ microbial metabolism in diverse environments, MP $=$ metabolic pathways, and GLD = glyoxylate and dicarboxylate metabolism.

are related to the transformation of nitroalkane, nitrate and nitrite into ammonia, were detected in the proteomes. NMO (A1A109247.1) stimulated the conversion of nitroalkane into nitrite and increased by 2.13 -fold in TCI compared with that observed in TI. Also, SO (A1A106983.1), which could promote the conversion of $\mathrm{NO}_{3}{ }^{-}$to $\mathrm{NO}_{2}{ }^{-}$, was determined to increase by 1.03 -fold in TCI. The proteomic data also showed that MDHAR (A1A105864.1) was upregulated by 4.02 -fold in TCI, which could convert $\mathrm{NO}_{2}{ }^{-}$into ammonia. Moreover, nitrile could be transformed to ammonia via two nitrilases (A1A101490.1 and A1A107668.1), and the results indicated that these enzymes were also strongly upregulated by 2.49 - and 9.81-fold, respectively, in TCI. In addition, another two pathways (glutamate or proline to ammonia and urea to ammonia) were also analyzed, and the results indicated that enzymes such as glutamate dehydrogenase, cystathionine $\gamma$-lyase, and cystathionine $\beta$-lyase were all upregulated in NJAU 4742 after interacting with cucumber roots. Ammonium transporters were observed to increase by 3.24- and 3.56-fold, which indicated that the NJAU 4742 strain had a considerable ability to adjust the balance of ammonium, thereby decreasing ammonium toxicity. The results described above implied that the auxin biosynthesis and ammonification level of NJAU 4742 could be directly influenced by the interaction with cucumber roots, in which auxin biosynthesis, shikimate metabolism, nitrogen metabolism, and peroxisomes appeared to play important roles.

In situ studies of the auxin biosynthesis mechanism and intracellular ammonification process in the NJAU 4742 strain.

To verify whether auxin biosynthesis could truly reflect the condition of the NJAU 4742 strain, more thorough research, 
Table 1. (Continued from previous page)

\begin{tabular}{|c|c|c|c|c|}
\hline Biological function & Pathway $^{b}$ & FC & $P$ value & Sig \\
\hline $\begin{array}{l}\text { TCI/TI (continued) } \\
\text { Hydrolyzing O-glycosyl compounds; carbohydrate metabolic process } \\
\text { Hydrolyzing O-glycosyl compounds; } \beta \text {-N-acetylhexosaminidase activity } \\
\text { Acting on carbon-nitrogen bonds; nitrogen compound metabolic process } \\
\text { Oxidoreductase activity, acting on paired donors; binding oxidation-reduction process } \\
\text { Oxidoreductase activity, acting on paired donors; binding oxidation-reduction process } \\
\text { Polyketide synthase dehydratase; AMP-binding enzyme } \\
\text { GTP binding; small GTPase mediated signal transduction } \\
\text { Catalytic activity, carbohydrate binding; carbohydrate metabolic process } \\
\text { Oxidoreductase activity; oxidation-reduction process } \\
\text { Nucleosome, DNA binding; protein heterodimerization activity } \\
\text { Oxidoreductase activity; oxidation-reduction process }\end{array}$ & $\begin{array}{c}\text { SSM } \\
\text { GLD } \\
\text { TRP/NIT } \\
\text { MP } \\
\text { MME } \\
- \\
- \\
\text { SSM } \\
\text { SSM } \\
- \\
-\end{array}$ & $\begin{array}{r}14.053 \\
8.981 \\
9.787 \\
13.573 \\
8.487 \\
6.625 \\
6.433 \\
8.721 \\
8.377 \\
6.989 \\
6.246\end{array}$ & $\begin{array}{l}0.000153 \\
0.009271 \\
0.000141 \\
0.002722 \\
0.000005 \\
0.002334 \\
0.000050 \\
0.017427 \\
0.000141 \\
0.044956 \\
0.003320\end{array}$ & $\begin{array}{l}\text { No } \\
\text { No } \\
\text { No } \\
\text { No } \\
\text { No } \\
\text { No } \\
\text { No } \\
\text { No } \\
\text { No } \\
\text { No } \\
\text { No }\end{array}$ \\
\hline $\begin{array}{l}\text { TCE/TE (continued) } \\
\text { Hydrolyze glucosidic bonds, releasing glucose } \\
\text { Hydrolyzing O-glycosyl compounds; carbohydrate metabolic process } \\
\text { Hydrolyzing O-glycosyl compounds; carbohydrate metabolic process } \\
\text { Hydrolyzing O-glycosyl compounds; extracellular region cellulose binding } \\
\text { Hydrolyzing O-glycosyl compounds, chitinase activity } \\
\text { Restore cell wall expansion activity; nonenzymatic cell wall active protein } \\
\text { Response to oxidative stress; heme binding, oxidation reduction } \\
\text { Response to oxidative stress; heme binding, oxidation reduction } \\
\text { Response to oxidative stress; heme binding, oxidation reduction } \\
\text { Response to oxidative stress; heme binding, oxidation reduction } \\
\text { ATP binding, DNA replication, DNA repair } \\
\text { Control cell division } \\
\text { Heterokaryon incompatibility protein; ankyrin repeats (three copies) } \\
\text { Multifunctional calcium-binding glycoprotein } \\
\text { Identify the receptor; transmit signals; binding to the cell wall chitin } \\
\text { ATP binding, cytoplasm } \\
\text { Protein binding }\end{array}$ & $\begin{array}{c}\text { PHE/BSM } \\
\text { PHE/BSM } \\
\text { PHE/BSM } \\
\text { PHE/BSM } \\
\text { PHE/BSM } \\
\text { PHE/BSM } \\
\text { PHE/BSM } \\
- \\
\text { PPI } \\
- \\
- \\
- \\
- \\
- \\
\text { SSM/PHE } \\
\text { PHE/BSM } \\
-\end{array}$ & $\begin{array}{l}3.830 \\
3.770 \\
3.860 \\
2.070 \\
0.500 \\
2.290 \\
2.670 \\
2.470 \\
2.010 \\
0.440 \\
0.490 \\
0.450 \\
0.300 \\
2.990 \\
8.850 \\
2.650 \\
0.300\end{array}$ & $\begin{array}{l}0.000006 \\
0.000007 \\
0.000308 \\
0.003347 \\
0.000018 \\
0.026323 \\
0.007990 \\
0.000656 \\
0.004094 \\
0.024212 \\
0.000299 \\
0.000024 \\
0.001882 \\
0.000867 \\
0.004117 \\
0.000045 \\
0.001882\end{array}$ & $\begin{array}{l}\text { Yes } \\
\text { Yes } \\
\text { Yes } \\
\text { Yes } \\
\text { Yes } \\
\text { Yes } \\
\text { Yes } \\
\text { Yes } \\
\text { Yes } \\
\text { Yes } \\
\text { Yes } \\
\text { Yes } \\
\text { Yes } \\
\text { Yes } \\
\text { Yes } \\
\text { Yes } \\
\text { Yes }\end{array}$ \\
\hline $\begin{array}{l}\text { TCE/CE (continued) } \\
\text { Attack pathogenesis } \\
\text { Attack pathogenesis } \\
\text { Hydrolyzing O-glycosyl compounds } \\
\text { Response to oxidative stress } \\
\text { Carbohydrate metabolic process } \\
\text { Response to oxidative stress } \\
\text { Attack pathogenesis } \\
\text { Restore cell wall expansion activity } \\
\text { Carbohydrate metabolic process } \\
\text { Response to oxidative stress } \\
\text { Response to oxidative stress } \\
\text { Hydrolyzing O-glycosyl compounds }\end{array}$ & $\begin{array}{l}- \\
\text { BSM } \\
\text { BSM } \\
\text { PHE/BSM } \\
\text { BSM } \\
\text { BSM } \\
\text { PEO } \\
\text { BSM } \\
\text { PHE/BSM } \\
\text { PHE/BSM } \\
\text { PEO } \\
\text { PEO } \\
\text { PHE/BSM }\end{array}$ & $\begin{array}{l}0.13 \\
0.33 \\
0.38 \\
0.4 \\
0.48 \\
0.54 \\
0.58 \\
0.69 \\
0.71 \\
0.73 \\
1.32 \\
1.6 \\
1.72\end{array}$ & $\begin{array}{l}0.001242 \\
0.001159 \\
1.41 \mathrm{E}-05 \\
7.11 \mathrm{E}-05 \\
0.004295 \\
0.002577 \\
0.002294 \\
0.002805 \\
0.004988 \\
0.001055 \\
0.013377 \\
0.001115 \\
0.011102\end{array}$ & $\begin{array}{l}\text { Yes } \\
\text { Yes } \\
\text { Yes } \\
\text { Yes } \\
\text { Yes } \\
\text { Yes } \\
\text { Yes } \\
\text { Yes } \\
\text { Yes } \\
\text { Yes } \\
\text { Yes } \\
\text { Yes } \\
\text { Yes }\end{array}$ \\
\hline
\end{tabular}

including critical gene expression analysis, auxin content determination, and cucumber biomass evaluation, was performed (Fig. 6). Most of the genes involved in auxin biosynthesis in the NJAU 4742 strain were selected to determine their contribution to this pathway (Fig. 6A). The results of quantitative fluorescence detection showed that chorismate mutase and tryptophan synthase genes increased by 6.12- and 2.74-fold, respectively (Fig. $6 \mathrm{~B})$. In particular, the nitrilase, amidase, aldehyde dehydrogenase 1, and aldehyde dehydrogenase 2 genes exhibited notably increased transcription levels of 53.4-, 38.1-, 4.72-, and 2.30-fold, respectively, after interacting with cucumber roots. The auxin content in cucumber roots from the hydroponic system was determined (Fig. 6C and D). Based on the result analysis of auxin contents in cucumber roots at different time points, we observed that the NJAU 4742 strain could significantly increase the auxin content, which was higher than that of the cucumber culture control (CK) and IAA treatments. Notably, the IAA treatment yielded the highest auxin content in the liquid medium compared with that in the other two treatments after 5 days. However, the auxin content in the NJAU 4742 treatment exhibited a gradually increasing trend, especially on the 30 th day, and the auxin content significantly increased by 1.15 - and 0.5 -fold compared with the $\mathrm{CK}$ and IAA treatments, respectively. All of these results clearly indicated that IAA biosynthesis in NJAU 4742 was enhanced significantly after interacting with cucumber roots, which might be an important plant-growth-promoting mechanism.

As a kind of available nitrogen, ammonia can be absorbed by various plants, and ammonium excretion by the NJAU 4742 strain could represent a possible mechanism of promoting plant growth (Fig. 7B). The fluorescence quantification results of the critical genes involved in the synthesis and secretion of ammonium indicated that all of these genes, including cystathionine $\gamma$-lyase (cgll), ammoniate transporter, cystathionine $\beta$-lyase, sulfite oxidase, monodehydroascorbate reductase, nitronate monooxygenase (nmo), glutamate dehydrogenase (gdl), nitrilase, and arginase ( $\arg$ ), were significantly upregulated with NJAU 4742 treatment (Fig. 7B). Among these genes, cgll, arg, gdl, and nmo exhibited higher expression levels in the TC treatment than in the $\mathrm{C}$ treatment, and the relative expression levels increased 197.4-, 127.3-, 203.5-, and 154.1-fold, respectively. These results were highly consistent with the results of proteomic analysis. ${ }^{15} \mathrm{~N}$-labeled $\mathrm{KNO}_{3}$ was employed to further investigate ammonia 
synthesis and secretion of the NJAU 4742 strain, and it was shown that both the NJAU 4742 strain and cucumber roots could absorb ${ }^{15} \mathrm{~N}-\mathrm{KNO}_{3}$. In addition, ${ }^{15} \mathrm{~N}_{-} \mathrm{NH}_{4}{ }^{+}$was detected in the $\mathrm{C}$ and TC treatments after 25 days at abundances of 4.47 and $5.30 \%$, respectively. Meanwhile, the abundance of ${ }^{15} \mathrm{~N}_{-} \mathrm{NH}_{4}{ }^{+}$in the $\mathrm{T}$ treatment was only $0.23 \%$, which was almost below the detection limit (Fig. 7D). The abundance of ${ }^{15} \mathrm{~N}$-total nitrogen in the plant roots was also determined, and the results showed that there was a significant difference between the TC (23.6\%) and C $(11.3 \%)$ treatments after cocultivation for 25 days (Fig. 7E). In brief, these results indicated that the intracellular ammonia synthesis and secretion capacity of the NJAU 4742 strain could be improved after interacting with cucumber roots.

\section{DISCUSSION}

In this study, the interaction between cucumber roots and the NJAU 4742 fungal strain in a hydroponic system was explored. The total proteins of NJAU 4742 and secretomes of cucumber roots growing alone or in association were also identified. Furthermore, the identities and functions of these proteins were analyzed to demonstrate the molecular interaction between NJAU 4742 and cucumber roots and elucidate the roles played by various proteins during this symbiotic interaction.

\section{Effect of Trichoderma spp. in promoting plant growth.}

Previous reports determined that $T$. virens could colonize plant roots, and this fungus had been applied in various host plants due to its positive effect on plant growth and productivity (Nieto-Jacobo et al. 2017; Singh et al. 2016). Our results demonstrated that NJAU 4742 could increase the plant biomass and regulate the root morphology by accelerating lateral root formation, which suggested that NJAU 4742 could promote cucumber growth by regulating different metabolism and signal substances during interactions with the host root system. Many studies have reported that ACCD, peroxidase, Epl1 protein, Sm1 protein, TVHYDII1 protein, and mitogen-activated protein kinase 6 from Trichoderma spp. were upregulated after interaction with the host, which could differentially increase plant growth (Guzmán-Guzmán et al. 2017; Nogueira-Lopez et al. 2018; Salas-Marina et al. 2015). The signaling pathways or secondary metabolites identified from Trichoderma spp. in the microbeplant interaction system were involved in cucumber root-system architecture alterations (Contreras-Cornejo et al. 2015; GarnicaVergara et al. 2016). Trichoderma spp. might employ similar mechanisms to regulate root morphology under coculture conditions. Therefore, elucidating the molecular mechanisms governing specific metabolic pathways of Trichoderma spp. may facilitate the manipulation of host root morphology.

\section{Intracellular proteins obtained from NJAU 4742 during the interaction with cucumber roots.}

The identified NJAU 4742 proteins associated with protein metabolism, carbon or energy, and secondary metabolism during the interaction with cucumber roots were analyzed by the SWATH approach. These metabolic pathways were previously reported to participate in the molecular mechanisms governing microbe elicitor activation (Lombardi et al. 2020), which suggested that Trichoderma spp. could produce secondary metabolites with several biological activities to influence plant

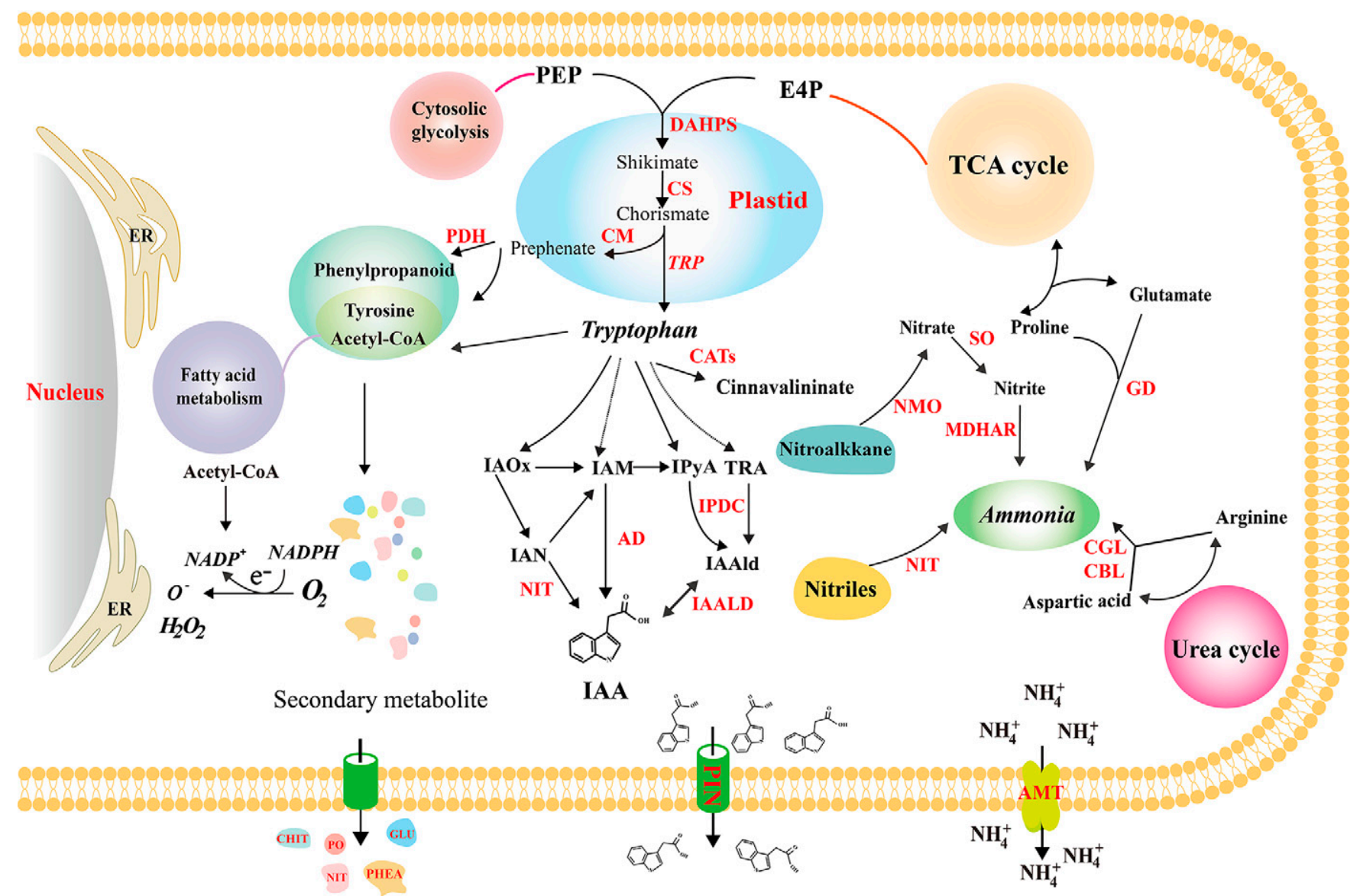

Fig. 5. Metabolism schematic of various pathways in strain NJAU 4742 after interacting with cucumber roots. Differentially changed proteins involved in the vital pathways are labeled in red; CAT $=$ catalase; NIT $=$ nitrilase; CHIT $=$ chitinases; PHEA $=$ phenylalanine ammonialyase; GLU $=\beta-1,3-$ glucanase; PO = peroxidase; and SSCPs = small, secreted, cysteine-rich proteins. 
metabolism. Notably, the overexpressed intracellular proteins were primarily related to shikimate metabolism (L-tryptophan, L-phenylalanine, and L-tyrosine), auxin biosynthesis, and nitrogen metabolism, except for the energy metabolic pathways. Among these pathways, the aromatic amino acid (AAA) pathway was believed to play important roles in UV protection, electron transport, signaling, communication, plant defense, structural components, and the wound response by providing the basic building blocks for the synthesis of aromatic compounds (Tzin and Galili 2010). The AAA pathway generally participated in the synthesis of numerous natural products, including pigments, alkaloids, flavonoids, hormones, lignin, aromatic antibiotics, and cell wall components (Rodriguez et al. 2015; Tohge et al. 2013). The chorismate mutases of the AAA pathway from Trichoderma spp. were detected, and they were also found in many plant-associated microbes to serve as general tools for host manipulation by changing the metabolic status (Djamei et al. 2011). Rivas-San Vicente and Plasencia (2011) noted that more salicylic acids were produced after interacting with the host, which resulted in lower chlorophyll contents and growth-stimulating effects due to its function as endogenous signal-mediating local and systemic plant defense responses to pathogens and abiotic stresses (e.g., drought, chilling, heavy metal toxicity, heat, and osmotic stress). Many proteins in the AAA pathway were identified in this study, and they were able to participate in the synthesis of different metabolites, including cinnavalininate, kynurenine,
A

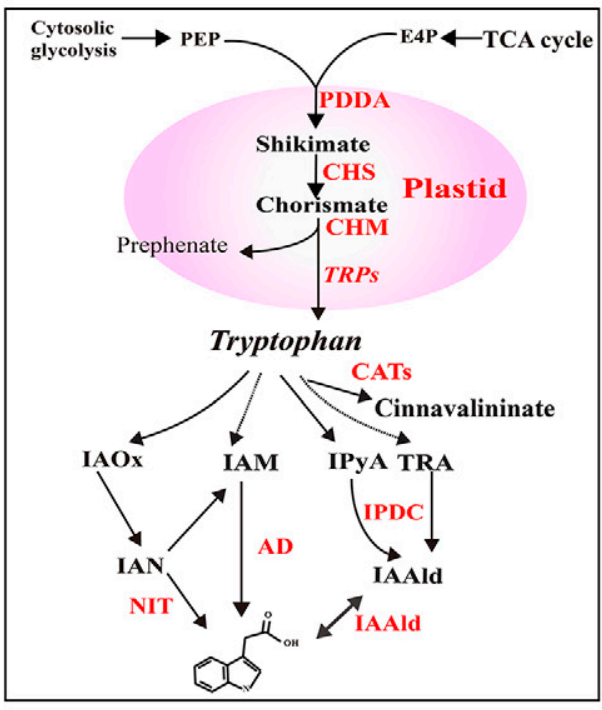

C

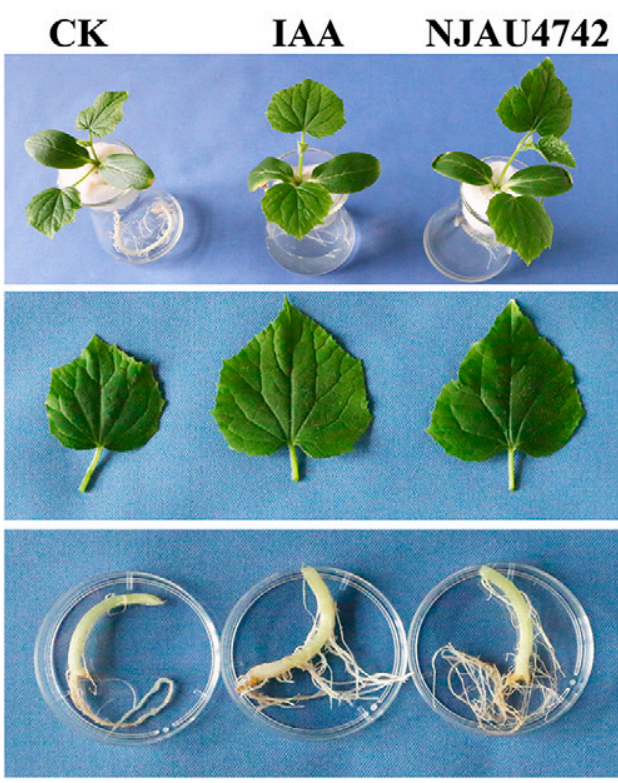

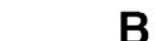

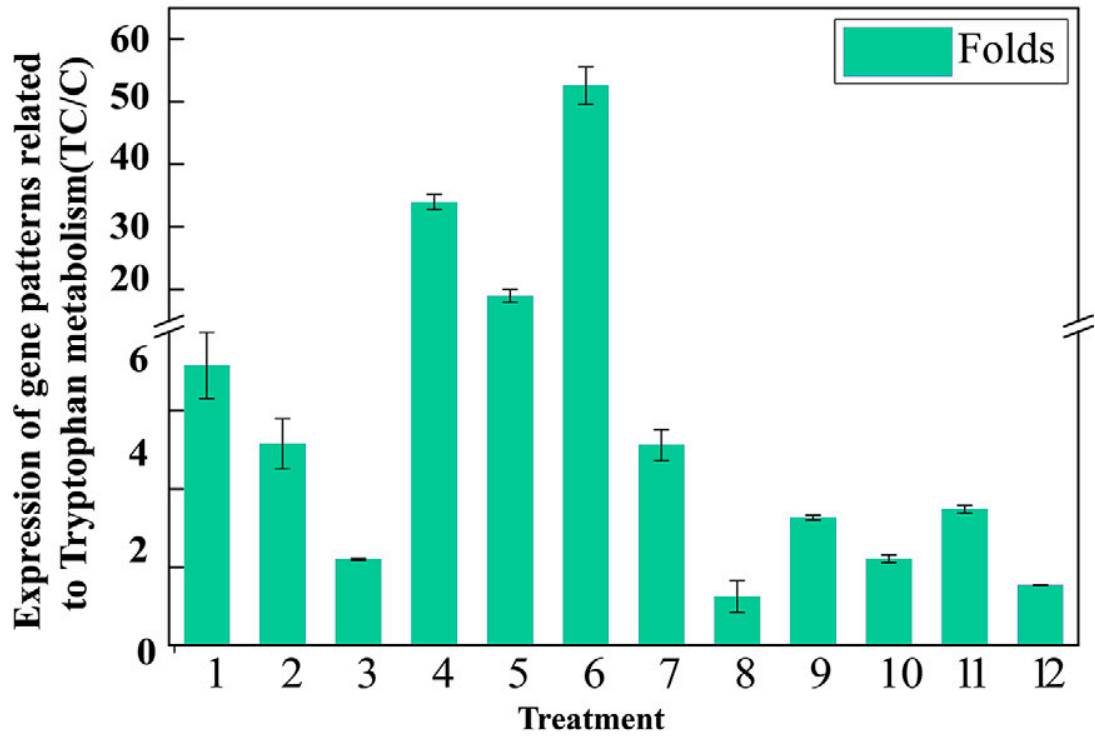

D

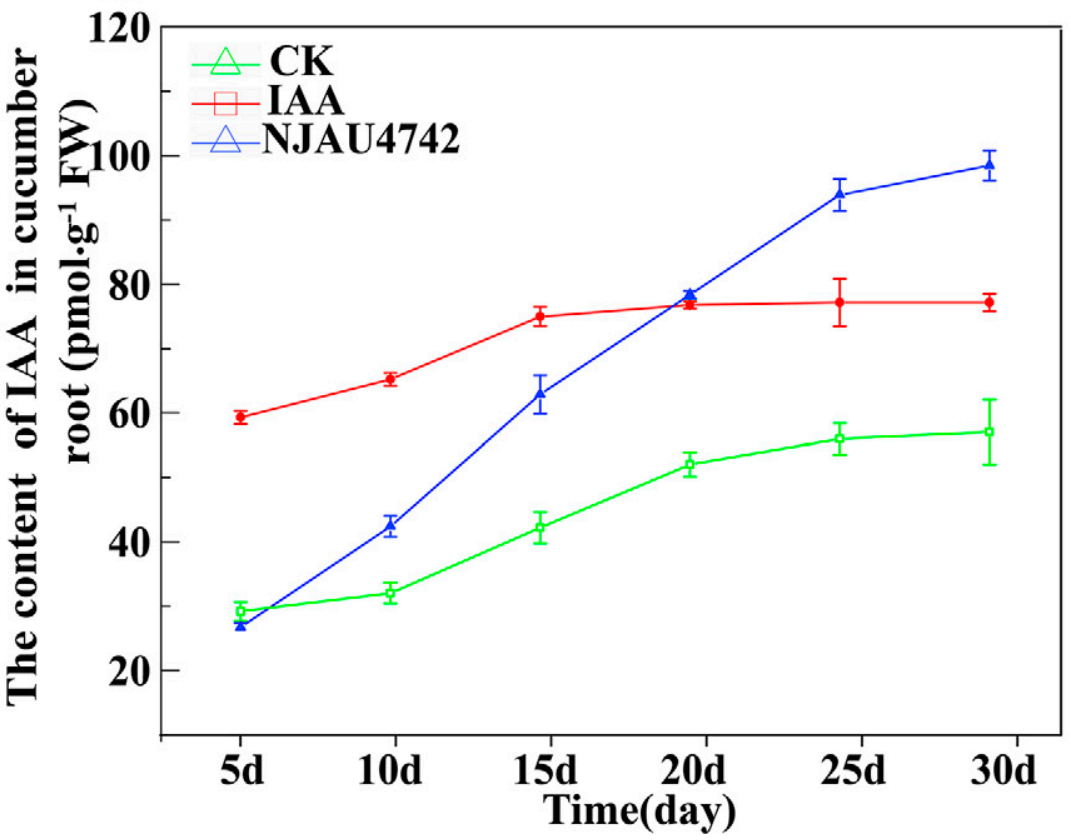

Fig. 6. In situ study results of the auxin biosynthesis mechanism in strain NJAU 4742. A, Differentially regulated proteins involved in shikimate metabolism pathway. B, Transcriptional levels of vital genes related to shikimate pathways: $1=$ tryptophan synthase (trps); $2=$ aldehyde dehydrogenase 1 (ald1); 3 = aldehyde dehydrogenase 2 (ald2); $4=$ amidase (ad); $5=$ indole pyruvate dehydrogenase (ipdc); $6=$ nitrilase 1 (nit1); $7=$ nitrilase 2 (nit2); $8=$ chorismate synthase $(\mathrm{chs}) ; 9=$ chorismate mutase $(\mathrm{cmm}) ; 10=$ catalase $(\mathrm{cat}) ; 11=$ aminotransferase $($ amt $)$; and $12=$ phospho deoxyheptonate al dolase $(p d d a) . \mathrm{TC}=$ cucumber roots grown with NJAU 4742 and $\mathrm{C}=$ cucumber grown without NJAU 4742. C and D, Variations of indole-3-acetic acid (IAA) content of cucumber root in different treatments. $\mathrm{CK}=$ the pure culture of cucumber seedings, IAA $=$ addition of IAA at a final concentration of $200 \mu \mathrm{M}$, and NJAU $4742=$ the treatment inoculated with strain NJAU 4742. 
alkaloids, camalexin, and pyrrolizidine. These findings suggested that NJAU 4742 could respond to cucumber roots by regulating proteins related to signaling pathways. These compounds performed vital functions in plant defense against biotic and abiotic stresses and the environment during fungal colonization, as reviewed by Maeda and Dudareva (2012).

Additionally, 3-deoxy-D-arabino-heptulosonate 7-phosphate (DAHP) synthase was upregulated in TCI treatment, and Tzin and Galili (2010) found that DAHP primarily participated in regulating the cellular metabolism level of AAAs and was essential for microbial metabolism and energy supply. For 5-enolpyruvyl shikimate 3phosphate synthase (EPSPS) and CS, the high expression of these two proteins would accelerate the metabolism of the shikimate pathway and might provide precursors for increasing a variety of hormones such as auxin and salicylate, or a very wide range of aromatic secondary metabolites (Tohge et al. 2013). Similar results, in which EPSPS and CS were dramatically upregulated, were also obtained in the NJAU 4742 strain, suggesting that enhancing the metabolism level of the shikimate pathway could be one of the plant-growthpromoting mechanisms employed by the NJAU 4742 strain.

Remarkably, nine of the identified intracellular proteins of the AAA pathway were related to Trp and auxin metabolism, which implied that the colonization of NJAU 4742 was a response to the cucumber roots during the microbe-plant interaction process. Tzin and Galili (2010) reported that indole-3-glycerol-phosphate synthase (IGPS) was the only known enzyme that formed the indole ring in Trp metabolism, which indicated that the increased IGPS in NJAU 4742 could accelerate the formation of the indole ring for auxin biosynthesis. Additionally, the upregulated 3-hydroxyanthranilic acid dioxygenase in NJAU 4742 could catalyze the conversion of the intermediate product (aminomuconate) into acetyl-CoA, which suggested that it could improve the basic energy metabolism level of NJAU 4742 to minimize the impact of nutrient competition with plants. A high content of
A

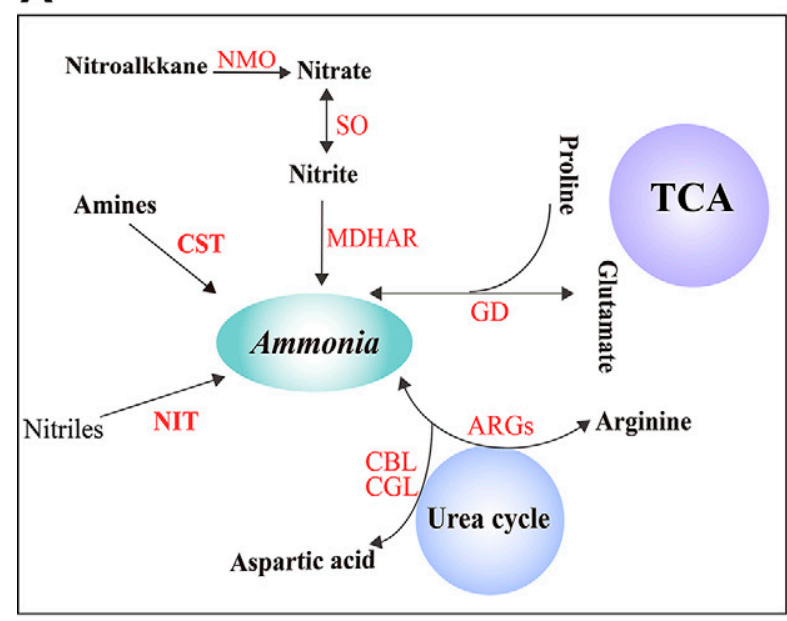

C

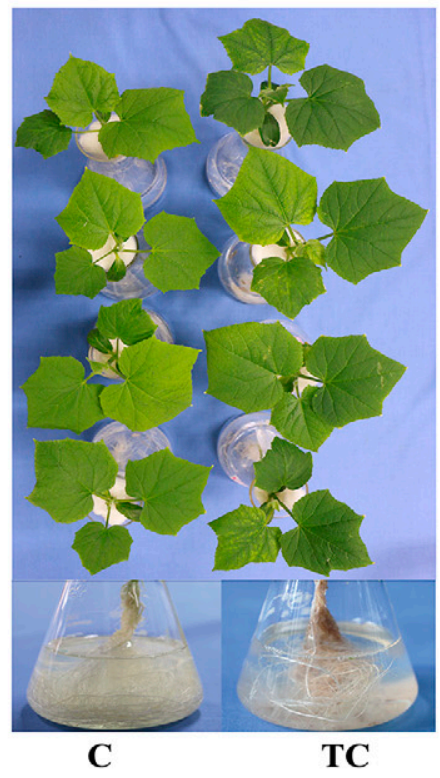

D

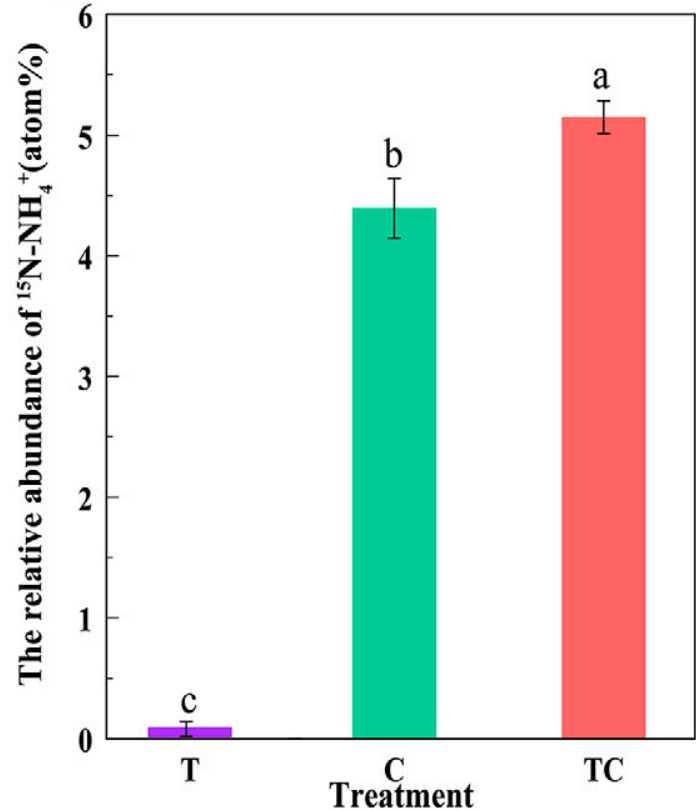

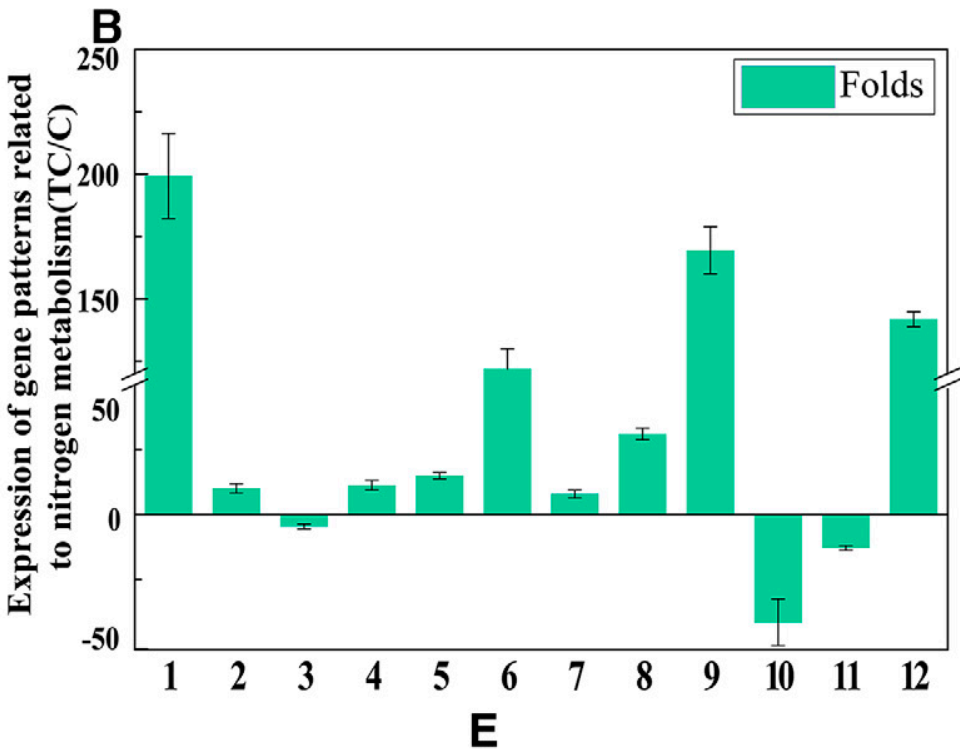

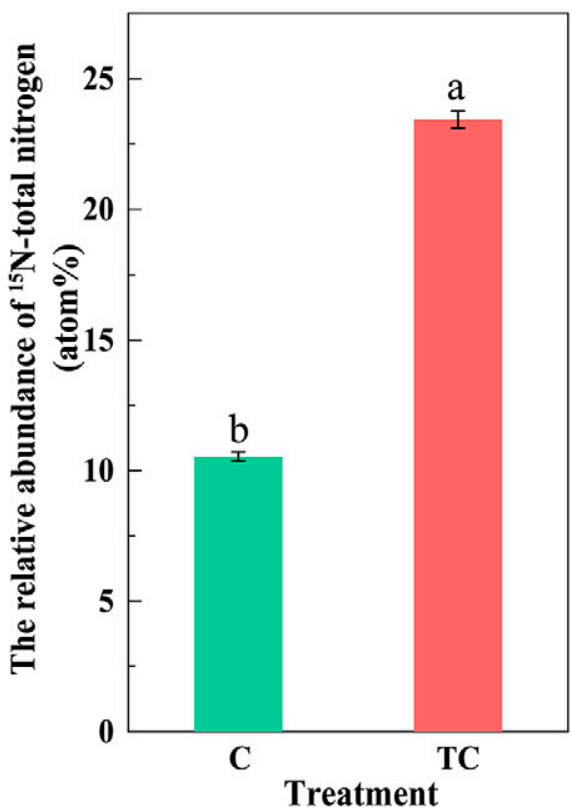

Fig. 7. Nitrogen metabolism pathway and ammonification characterization in strain NJAU 4742. A, differentially regulated proteins involved in nitrogen metabolism. B, Transcriptional level of the genes involved in nitrogen metabolism pathway by PCR: $1=$ cystathionine $\beta$-lyase1 (cbl1); 2 = cystathionine $\beta$-lyase 2 (cbl2) $3=$ argininosuccinate lyase (arl); $4=$ cystathionine $\gamma$ lyase1 (cgl); $5=$ nitrilase (nit); $6=$ arginase (arg); $7=$ sulfite oxidase (so); $8=$ monodehydroas reductase (mdhar); $9=$ glutamate dehydrogenase 1 ( $g d 1) ; 10=$ glutamate dehydrogenase 2 (gd2); $11=$ aminotransferase (amt); and $12=$ nitronate monooxygenase 2 (nmo). TC = cucumber roots grown with NJAU 4742 and C $=$ cucumber grown without NJAU 4742 $\mathbf{C}$ and $\mathbf{D}$, Abundance of ${ }^{15} \mathrm{~N}_{-} \mathrm{NH}_{4}{ }^{+}$in the liquid medium after 25 days. E, Abundance of ${ }^{15} \mathrm{~N}$-nitrogen in cucumber after inoculating with NJAU 4742. 
acetyl-CoA could promote colonization and plant growth. Therefore, it is plausible that the regulation of the Trp synthesis pathway could serve as a component of the basal mechanism governing the promotion of host growth.

Proteins involved in phytohormone signaling were also identified, and they were determined to be responsible for the biosynthesis of the precursor of the auxin biosynthesis pathway. The upregulated proteins could also enhance the accumulation of auxin in the rhizosphere after interacting with plant roots, which was in keeping with the results reported by Nieto-Jacobo et al. (2017). Concurrently, IAA could mediate root architectural changes by accelerating the formation of apical dominance, initiation of lateral and adventitious roots, regulation of root morphology, cell division, and cell expansion (Verma et al. 2016). Furthermore, proteins involved in the ammonification pathway were also significantly upregulated, enabling nitrate or nitrite reductase to enhance dissimilation or assimilation in NJAU 4742. Notably, NJAU 4742 possessed a considerable capacity for nitrate reduction, which was also observed previously in anaerobic ammonium-oxidizing microbes (anammox) based on proteomics (Kartal et al. 2007). Nevertheless, Epsilonproteobacteria could reduce the transformations of nitrite and hydroxylamine into ammonium (Haase et al. 2017), and certain fungi also exhibited interesting features of inhibiting dissimilatory nitrate reduction to ammonia (Suzuki 2009). As components of another ammonia-producing pathway, nitrogen-related amino acids could also be transformed into ammonia in NJAU 4742, as supported by the results that argininosuccinate synthase, argininosuccinate lyase, and arginase were also upregulated in TCI compared with their levels in TI. Arginine degradation is one of the amino acid metabolism pathways in which arginine is typically decomposed into urea by arginases and, finally, into ammonia (Fujii et al. 2019). In this study, arginases exhibited significant upregulation at both the transcriptomic and proteomic levels, which demonstrated that arginases might be a critical parameter for ammonification. A previous study reported that ammonia from microbes was very beneficial for plants when colonizing plant roots. Notably, ammonium ions were considered to be signaling substances involved in the interactions between plant-growth-promoting fungi and plants (Narula et al. 2009). Even though the conjugation effect of ammonium ions as signaling substances or nutrients for plants has not been elucidated, a deeper investigation of the molecular mechanism governing ammonium production is merited.

\section{Secretomes of NJAU 4742 and cucumber roots during the interaction process.}

Some extracellular functional proteins (antioxidant proteins, GH family, $\beta$-glucosidase, expansion-like proteins, chitinase, and secondary metabolism proteins) (Supplementary Dataset S2) secreted by NJAU 4742 were significantly regulated in TCE compared with TE; among these proteins, GHs and $\beta$-glucosidase exhibited the highest levels. These results provide important evidence that NJAU 4742 might colonize the outer root surface by secreting $\beta$-glucosidases to degrade the host cell walls and subsequently occupy this ecological niche. These results were consistent with the findings of previous studies, which observed that GHs could directly influence the colonization of $T$. virens on plant roots and then improve plant defense (Morán-Diez et al. 2015; Lamdan et al. 2015). Also, Rubio et al. (2012) found that the genes of Trichoderma spp. involved in carbohydrate metabolism, nutrient exchange with the plant, building block generation, and cell wall synthesis were upregulated after interacting with tomato. Taken together, these findings indicated that Trichoderma spp. could secrete various enzymes and were necessary for colonizing host tissues or loose cell walls to promote root growth and regulate root architecture.
Some Trichoderma strains exhibited a better ability to tolerate oxidative stress than many other soilborne organisms and obtained an advantage over other rhizosphere residents in surviving in the rhizosphere ecosystem by upregulating peroxidase (Morán-Diez et al. 2010). Dietz (2016) also found that upregulated peroxidase could participate in the scavenging of oxygen species (ROS) and immune response of the plant, which could enhance the stress resistance and photosynthetic capacity without causing damage to beneficial microbes. Additionally, some peroxidases in cucumber roots were also upregulated in the TCE treatment compared with the $\mathrm{CE}$ treatment. Typically, peroxidases are the principal components in the plant defense response against pathogens. These enzymes may strengthen the plant cell walls or induce plant oxidative bursts in the apoplast and create suitable conditions for microbe interactions (Brotman et al. 2013). Several pathogenesis-related (PR)-like proteins (Table 1; Supplementary Dataset S3) were also identified in CE treatment, which suggested that these functional proteins could be specifically induced by the colonization of $T$. virens. Parallel findings were observed during the interaction between $T$. atroviride and host plants, where PR proteins were specifically activated for recognition (Marra et al. 2006). These findings indicated that Trichoderma spp. can secrete enzymes to interact with plant root, which may represent a strategy for maintaining ROS stability to influence further plant immune responses.

\section{MATERIALS AND METHODS}

\section{Cucumber germination.}

Cucumber seed (Cucumis sativus L. 'Jinchun-No. 4' obtained from Tianjin Cucumber Research Center, China) were surface sterilized with $75 \%$ ( $\mathrm{vol} / \mathrm{vol}$ ) ethanol for $1 \mathrm{~min}$ followed by $10 \%$ ( $\mathrm{vol} / \mathrm{vol}$ ) sodium hypochlorite for $20 \mathrm{~min}$, and the seed were subsequently washed three times with sterile water. The cucumber seed were placed in sterile Petri dishes containing $0.2 \times \mathrm{MS}$ and incubated in the dark for $36 \mathrm{~h}$ at $30^{\circ} \mathrm{C}$ for germination. The germinated seed were cultured with $0.2 \times$ MS solution in a humidity-controlled plant growth chamber for 7 days, and the culture conditions were set as $25^{\circ} \mathrm{C}, 80 \%$ humidity, and $16 \mathrm{~h}$ of light and $8 \mathrm{~h}$ of darkness per cycle.

\section{Inoculum preparation.}

T. guizhouense NJAU 4742 was originally isolated from a mature compost sample, and its genome sequence has already been published in the NCBI database (accession number LVVK00000000.1). Spore suspensions were obtained after cultivation on potato dextrose agar for 7 days and later diluted to $1 \times 10^{6}$ spores $\cdot \mathrm{ml}^{-1}$. Next, NJAU 4742 spores were inoculated into MS liquid medium (1:100, vol/vol) with $1 \%$ (wt/vol) glucose in a 500-ml triangular flask and cultured at $28^{\circ} \mathrm{C}$ and 180 $\mathrm{rpm}$ for $24 \mathrm{~h}$. The newly germinated spores were filtered with a filter membrane $(0.45 \mu \mathrm{m})$, then washed twice with $100 \mathrm{ml}$ of sterile distilled water. The newly germinated spores were resuspended in $5 \mathrm{ml}$ of $0.2 \times \mathrm{MS}$ solution for the subsequent experiment.

\section{Inoculation of NJAU 4742 to cucumber roots.}

In total, 50 germinated seedlings with similar-sized roots and shoots were placed on the stands in each 250-ml triangular flask containing $100 \mathrm{ml}$ of $0.2 \times$ MS liquid medium. After 4 days of cultivation, the $0.2 \times$ MS was replaced by fresh medium, and the preprepared newly germinated spores were inoculated into the cucumber roots. The plants were maintained in an artificial climate chamber with the following conditions: a photoperiod of 16 and $8 \mathrm{~h}$ at 26 and $22^{\circ} \mathrm{C}$, respectively, assuring photosynthetic photon flux density of $300 \mu \mathrm{mol} \mathrm{m} \mathrm{m}^{-2}$, constant relative humidity of $80 \%$, and moderate shaking on an 
orbital shaker (100 rpm) to furnish sufficient oxygen for NJAU 4742 growth. The growth medium was supplemented to 100 $\mathrm{ml}$ with fresh $0.2 \times \mathrm{MS}$ solution over time. Three different treatments, including $\mathrm{TC}, \mathrm{T}$, and $\mathrm{C}$, were performed.

\section{Protein extraction from different treatments.}

Samples from different treatments in hydroponic medium on the 25th day were used for protein extraction for proteome analysis. In total, 50 triangular flask replicates were performed for each treatment to collect enough samples. The liquid media from the coculture system TCE, TE, and CE were collected after 25 days, during which 16 randomly selected replicates from the same treatment were combined as a new replicate (three replicates for each treatment) to ensure enough proteins for LS-MS/ MS analysis. The combined solutions from different treatments were centrifuged at $10,000 \mathrm{rpm}$ for $10 \mathrm{~min}$ at $4^{\circ} \mathrm{C}$, and the supernatants were filtered through a $0.22-\mu \mathrm{m}$ filter (Millex-GP; Syringe-Driven Filter Unit, 041237-LRL-001). After that step, the filtered supernatants were concentrated by use of the ammonium sulfate precipitation method described by Wingfield (2016). The precipitates were redissolved in $0.5 \times$ phosphate-buffered saline (PBS; pH 7.0) and then transferred into a dialysis bag (MD443500D; Solarbio) in PBS (pH 7.0) overnight at $4^{\circ} \mathrm{C}$. The intracellular proteins of TCI and TI were also collected for LS-MS/MS analysis. Fifty individual triangular flasks were randomly divided into two parts; then, the separated triangular flasks were combined as a new replicate (two replicates for each treatment) for intracellular protein extraction. The intracellular proteins of NJAU 4742 mycelium from TCI and TI treatments were extracted according to Cilia et al. (2009), with some modifications. The mycelium was collected and washed three times with icecold $0.5 \times$ PBS ( $\mathrm{pH} 7.0$ ); then lysed in $50 \mu \mathrm{l}$ of modified RIPA buffer $(50 \mathrm{mM}$ Tris [pH 7.5], $150 \mathrm{mM} \mathrm{NaCl}, 1 \mathrm{mM}$ EDTA, $0.1 \%$ Na-deoxycholate, and $1 \%$ nonionic surfactant glycol octyl phenyl-polyethylene) containing protease and phosphatase inhibitors (A32959; Thermo Fisher). The mixtures were collected by centrifugation at $5,000 \mathrm{rpm}$ for $10 \mathrm{~min}$ at $4{ }^{\circ} \mathrm{C}$, and the lysates were transferred to clean 2-ml microcentrifuge tubes, then stored at $-80^{\circ} \mathrm{C}$ for the subsequent experiment. The frozen cells were ground into a fine powder in liquid nitrogen using a mortar and pestle, then resuspended in ice-cold extraction buffer $(500 \mathrm{mM}$ $\mathrm{NaCl}, 100 \mathrm{mM} N$-2-hydroxyethylpiperazine- $N N^{\prime}$-2-ethanesulfonic acid [pH 7.5], with $\mathrm{KOH}, 5 \mathrm{mM}$ EDTA, $1 \mathrm{mM}$ dithiothreitol, 5 $\mathrm{mM} \mathrm{NaF}$, polyvinyl pyrrolidone at $1 \mathrm{mg} \cdot \mathrm{ml}^{-1}, 0.4 \mathrm{mM}$ phenylmethylsulfonyl fluoride, and one tablet of protease inhibitor cocktail [Roche Complete Mini, EDTA-free] per $10 \mathrm{ml}$ of buffer) at $1 \mathrm{ml}$ per gram of fresh weight, after which the system was mixed thoroughly by vortexing and then incubated on a rotating platform for $1 \mathrm{~h}$ at $4^{\circ} \mathrm{C}$. TCA-acetone protein precipitation was applied to concentrate the proteins, and the extracts were resuspended in the remaining $2 \mathrm{ml}$ of PEM buffer $(0.1 \mathrm{M}$ piperazine- $N, N^{\prime}$-bis(2-ethanesulfonic acid), $2 \mathrm{mM}$ EGTA, and $1 \mathrm{mM}$ $\mathrm{MgSO}_{4}, \mathrm{pH}$ 8.5). Finally, the extracellular and intracellular protein contents were determined by the Bradford method (Kruger 2009) by using bovine serum albumin as a standard.

\section{Protein digestion and LC-MS/MS analysis.}

The SWATH analysis was applied to identify and quantify the proteins in different treatments as follows: $100 \mu \mathrm{g}$ of protein of each sample was digested by trypsin (GIBCO; Thermo Fisher) at $37^{\circ} \mathrm{C}$ overnight $(1: 50, \mathrm{wt} / \mathrm{wt})$, after which an equal volume of $0.1 \%$ formic acid (FA) was added to acidify the reaction system; peptides were loaded onto Strata-X C18 cartridges three times, washed with $0.1 \% \mathrm{FA}+5 \%$ acrylonitrile $(\mathrm{ACN})$ twice, and eluted with $1 \mathrm{ml}$ of $0.1 \% \mathrm{FA}+80 \% \mathrm{ACN}$; finally, the eluted peptides were dried using a vacuum concentration meter. LC-electrospray ionization-MS/MS analysis was performed on a
Triple TOF 5600 plus LC-MS/MS system (SCIEX, Ontario, Canada). Data-dependent acquisition was followed by SWATH acquisition with the same amount and gradient conditions; then, the peptides were loaded onto a C18 trap column $(5 \mu \mathrm{m}, 100$ $\mu \mathrm{m}$ by $20 \mathrm{~mm}$ ) with an elution rate of $300 \mathrm{nl} \cdot \mathrm{min}^{-1}$ onto a selfpacked C18 analytical column $(3 \mu \mathrm{m}, 75 \mu \mathrm{m}$ by $150 \mathrm{~mm})$ over a 120-min gradient. Buffer A (2\% acetonitrile, $0.1 \%$ FA, and $\left.98 \% \mathrm{H}_{2} \mathrm{O}\right)$ and buffer B $(98 \%$ acetonitrile, $0.1 \% \mathrm{FA}$, and $2 \%$ $\mathrm{H}_{2} \mathrm{O}$ ) were used as the mobile phases; MS1 and MS2 spectra were collected in the ranges of 350 to 1,500 and 100 to 1,500 $\mathrm{m} \cdot \mathrm{z}^{-1}$, respectively; and precursor ions were excluded from reselection for $15 \mathrm{~s}$. SWATH data were acquired with a 250-ms MS1 scan followed by $90-$ ms MS2 scans with $32 \times 25$ unified atomic mass unit (amu) isolation windows covering the mass range of 400 to $1,200 \mathrm{amu}$.

\section{SWATH data analysis.}

Spectral library generation and SWATH data processing were performed using skyline software (V3.5). Prior to targeted data extraction, a spectral library document was automatically generated complying with the rules implemented by Haudry et al. (2013) and used to create a decoy spectral library for targeting peak extraction. Based on the previous instructions, each ion was automatically extracted with a retention time width of 5 min, and the area under the curve for individual ions was calculated. Fragment ion areas belonging to one peptide were summed to obtain the peptide's abundance, and the summed peptide abundance of a specific protein was considered its abundance. All raw data among different treatments were normalized by using a median normalization method to eliminate random errors and sample bias (Oberg and Mahoney 2012). The mProphet algorithm was employed for each extracted peak by skyline software (V3.5) to assess the data confidence and control the FDR, and ProteoWizard (V3.0.9134) was used to transform Wiff files to the mzXML file type. Subsequently, SWATH targeted data analysis was completed by using OpenSWATH, which could automatically estimate the FDR by integrating a decoy scoring system and various peak group extractions by mProphet (Weisser et al. 2013). The peak groups obtained from SWATH maps at an FDR (1\%) and fold-change $\geq 2$ were aligned between different treatments based on the clustering behaviors of the retention time. Specifically, features were always considered alignment on the basis of a nonlinear alignment algorithm under the maximum FDR quality of $1 \%$ or the further constraint of a retention time difference of less than $60 \mathrm{~s}$ in the LC gradient after iRT normalization (Escher et al. 2012).

\section{Bioinformatic analysis.}

Signal peptides were identified using SignalP4 (Gomes et al. 2017). The CAZyme annotation was performed by HMMER software (Finn et al. 2015) with the dbCAN database. KEGG pathway annotation was performed using the KEGG OrthologyBased Annotation System 2.0 (Xie et al. 2011). GO annotation was also performed, and all differentially expressed proteins were assigned according to their biological process, cellular component, and molecular function. Cytoscape software (V3.5.1) was used to analyze PPIs based on the STRING database. All identified proteins in different treatments were separated by using a Venn diagram. All data were visualized according to the NJAU 4742 protein Atlas database and the cucumber genome database.

\section{Quantification of NJAU 4742}

\section{by quantitative reverse-transcription PCR.}

Based on the proteomic analysis results, the total RNA from the NJAU 4742 mycelium (TCI and TI) was extracted and then reverse transcribed into cDNA as a template. Quantitative 
reverse-transcription PCR was carried out on a PCR system (7500 fast real-time PCR system; Applied Biosystems) by using SYBR premix ExTaq II (TaKaRa, Dalian, China). The primers for verification of shikimate metabolism are listed in Supplementary Table S1, and the primers for verification of nitrogen metabolism are listed in Supplementary Table S2. Cycle threshold values were calculated with the $\beta$-tubulin gene as an endogenous control, and the data were expressed with the $2^{-\triangle \triangle \mathrm{Ct}}$ method (Livak and Schmittgen 2001). The auxin in the cucumber roots was extracted as follows: after liquid nitrogen grinding and high-speed centrifuging, the supernatants $(50 \mathrm{ml})$ of cucumber roots from the $\mathrm{TC}$ and $\mathrm{T}$ treatments were adjusted to $\mathrm{pH} 2.5$ with $1.0 \mathrm{M} \mathrm{HCl}$ and extracted three times with ethyl acetate $(1: 3, \mathrm{vol} / \mathrm{vol})$, with rotational evaporation at $30^{\circ} \mathrm{C}$, and the residue of organic solvents was dissolved in $1 \mathrm{ml}$ of methanol and filtered through a $0.22-\mu \mathrm{m}$ membrane filter. The quantification of the extracted auxin was performed with high-performance liquid chromatography by using a reversed-phase C18 analytical column ( 9.4 by $150 \mathrm{~mm}$; Agilent Technologies, Santa Clara, CA, U.S.A.) according to Chen et al. (2003). The characteristics of nitrogen transformation in the hydroponic system were determined by using ${ }^{15} \mathrm{~N}-\mathrm{KNO}_{3}$ as the sole nitrogen source, and the abundance of ${ }^{15} \mathrm{~N}$-total nitrogen in the plants was determined by using an automated isotope ratio mass spectrometer (IRMS; SERCON, 20-20, 209 UK), as described by Rashti et al. (2017). The relative abundance of ${ }^{15} \mathrm{~N}$-total in plants was calculated by the ratio of ${ }^{15} \mathrm{~N} /{ }^{15} \mathrm{~N}+{ }^{14} \mathrm{~N}$ (Herridge et al. 1990), while the relative abundance of secreted ${ }^{15} \mathrm{~N}_{-} \mathrm{NH}_{4}{ }^{+}$in the liquid medium of the T, C, and TC treatments was estimated from the ${ }^{15} \mathrm{~N}$-total nitrogen content by multiplying it based on the ratio of the calculated $\mathrm{NH}_{4}{ }^{+}$/total $\mathrm{N}$, as determined by a continuous flow analyzer (Auto Analyzer 3; Germany).

\section{AUTHOR-RECOMMENDED INTERNET RESOURCES}

Atlas database: http://bioinfo.njau.edu.cn/tgn4742/

Cucumber genome database:

https://www.ncbi.nlm.nih.gov/genome/?term=Cucumis+sativus STRING database: https://string-db.org/cgi/about

\section{ACKNOWLEDGMENTS}

We thank members of the Liu laboratories for their feedback and discussions.

\section{LITERATURE CITED}

Brotman, Y., Landau, U., Cuadros-Inostroza, Á., Tohge, T., Fernie, A. R., Chet, I., Viterbo, A., and Willmitzer, L. 2013. Trichodermaplant root colonization: Escaping early plant defense responses and activation of the antioxidant machinery for saline stress tolerance. PLoS Pathog. 9:e1003221.

Chen, K. S., Xu, C. J., Li, F., Chen, Q. J., and Zhang, S. L. 2003. An improved HPLC method for analyzing endogenous IAA and ABA in fruit tissues. J. Fruit Sci. 20:4-7 (in Chinese).

Cheng, C. H., Shen, B. N., Shang, Q. W., Liu, L. D., Peng, K. C., Chen, Y. H., Chen, F. F., Hu, S. F., Wang, Y. T., Wang, H. C., Wu, H. Y., Lo, C. T., and Lin, S. S. 2018. Gene-to-gene network analysis of the mediation of plant innate immunity by the eliciting plant response-like 1 (Epl1) elicitor of Trichoderma formosa. Mol. Plant-Microbe Interact. 31:683-691.

Cilia, M., Fish, T., Yang, X., McLaughlin, M., Thannhauser, T. W., and Gray, S. 2009. A comparison of protein extraction methods suitable for gel-based proteomic studies of aphid proteins. J. Biomol. Tech. 20:201-215.

Contreras-Cornejo, H. A., López-Bucio, J. S., Méndez-Bravo, A., Macías-Rodríguez, L., Ramos-Vega, M., Guevara-García, A. A., and López-Bucio, J. 2015. Mitogen-activated protein kinase 6 and ethylene and auxin signalling pathways are involved in Arabidopsis root-system architecture alterations by Trichoderma atroviride. Mol. Plant-Microbe Interact. 28:701-710.
Dietz, K. J. 2016. Thiol-based peroxidases and ascorbate peroxidases: Why plants rely on multiple peroxidase systems in the photosynthesizing chloroplast? Mol. Cells 39:20-25.

Djamei, A., Schipper, K., Rabe, F., Ghosh, A., Vincon, V., Kahnt, J., Osorio, S., Tohge, T., Fernie, A. R., Feussner, I., Feussner, K., Meinicke, P., Stierhof, Y.-D., Schwarz, H., Macek, B., Mann, M., and Kahmann, R. 2011. Metabolic priming by a secreted fungal effector. Nature 478:395-398.

Escher, C., Reiter, L., MacLean, B., Ossola, R., Herzog, F., Chilton, J., MacCoss, M. J., and Rinner, O. 2012. Using iRT, a normalized retention time for more targeted measurement of peptides. Proteomics 12:1111-1121.

Feldman, D., Yarden, O., and Hadar, Y. 2020. Seeking the roles for fungal small-secreted proteins in affecting saprophytic lifestyles. Front. Microbiol. 11:455.

Finn, R. D., Clements, J., Arndt, W., Miller, B. L., Wheeler, T. J., Schreiber, F., Bateman, A., and Eddy, S. R. 2015. HMMER web server: 2015 Update. Nucleic Acids Res. 43:W30-W38.

Fujii, K., Yamada, T., Hayakawa, C., Nakanishi, A., and Funakawa, S. 2019. Kinetics of arginine ammonification to estimate microbial activity of $\mathrm{N}$ mineralization in forest and cropland soils. Eur. J. Soil Biol. 92:1-7.

Garnica-Vergara, A., Barrera-Ortiz, S., Muñoz-Parra, E., Raya-González, J., Méndez-Bravo, A., Macías-Rodríguez, L., Ruiz-Herrera, L. F., and López-Bucio, J. 2016. The volatile 6-pentyl-2H-pyran-2-one from Trichoderma atroviride regulates Arabidopsis thaliana root morphogenesis via auxin signaling and ETHYLENE INSENSITIVE 2 functioning. New Phytol. 209:1496-1512.

Gomes, E. V., Ulhoa, C. J., Cardoza, R. E., Silva, R. N., and Gutiérrez, S. 2017. Involvement of Trichoderma harzianum Epl-1 protein in the regulation of Botrytis virulence- and tomato defense-related genes. Front. Plant Sci. 8:880

Gupta, R., and Bar, M. 2020. Plant immunity, priming, and systemic resistance as mechanisms for Trichoderma spp. Pages 81-110 in: Trichoderma. Rhizosphere Biology. A. K. Sharma and P. Sharma, eds. Springer, Singapore.

Guzmán-Guzmán, P., Alemán-Duarte, M. I., Delaye, L., Herrera-Estrella, A., and Olmedo-Monfil, V. 2017. Identification of effector-like proteins in Trichoderma spp. and role of a hydrophobin in the plantfungus interaction and mycoparasitism. BMC Genet. 18:16.

Haase, D., Hermann, B., Einsle, O., and Simon, J. 2017. Epsilonproteobacterial hydroxylamine oxidoreductase $(\varepsilon \mathrm{Hao})$ : Characterization of a 'missing link' in the multihaem cytochrome $c$ family. Mol. Microbiol. 105:127-138

Haudry, A., Platts, A. E., Vello, E., Hoen, D. R., Leclercq, M., Williamson, R. J., Forczek, E., Joly-Lopez, Z., Steffen, J. G., Hazzouri, K. M., Dewar, K., Stinchcombe, J. R., Schoen, D. J., Wang, X., Schmutz, J., Town, C. D., Edger, P. P., Pires, J. C., Schumaker, K. S., Jarvis, D. E., Mandáková, T., Lysak, M. A., van den Bergh, E., Schranz, M. E., Harrison, P. M., Moses, A. M., Bureau, T. E., Wright, S. I., and Blanchette, M. 2013. An atlas of over 90,000 conserved noncoding sequences provides insight into crucifer regulatory regions. Nat. Genet. 45:891-898.

Hermosa, R., Rubio, M. B., Cardoza, R. E., Nicolás, C., Monte, E., and Gutiérrez, S. 2013. The contribution of Trichoderma to balancing the costs of plant growth and defense. Int. Microbiol. 16:69-80.

Herridge, D. F., Bergersen, F. J., and Peoples, M. B. 1990. Measurement of nitrogen fixation by soybean in the field using the ureide and natural ${ }^{15} \mathrm{~N}$ abundance methods. Plant Physiol. 93:708-716.

Kartal, B., Kuypers, M. M., Lavik, G., Schalk, J., Op den Camp, H. J., Jetten, M. S., and Strous, M. 2007. Anammox bacteria disguised as denitrifiers: Nitrate reduction to dinitrogen gas via nitrite and ammonium. Environ. Microbiol. 9:635-642.

Kim, K.-T., Jeon, J., Choi, J., Cheong, K., Song, H., Choi, G., Kang, S., and Lee, Y.-H. 2016. Kingdom-wide analysis of fungal small secreted proteins (SSPs) reveals their potential role in host association. Front Plant Sci. 7:186.

Kruger, N. J. 2009. The Bradford method for protein quantitation. Pages 17-24 in: The Protein Protocols Handbook. J. M. Walker, ed. Springer Protocols Handbooks. Humana Press, Totowa, NJ, U.S.A.

Lamdan, N.-L., Shalaby, S., Ziv, T., Kenerley, C. M., and Horwitz, B. A. 2015. Secretome of Trichoderma interacting with maize roots: Role in induced systemic resistance. Mol. Cell. Proteomics 14:1054-1063.

Livak, K. J., and Schmittgen, T. D. 2001. Analysis of relative gene expression data using real-time quantitative PCR and the $2^{-\Delta \Delta C T}$ method. Methods 25:402-408.

Lombardi, N., Salzano, A. M., Troise, A. D., Scaloni, A., Vitaglione, P., Vinale, F., Marra, R., Caira, S., Lorito, M., d'Errico, G., Lanzuise, S., and Woo, S. L. 2020. Effect of Trichoderma bioactive metabolite 
treatments on the production, quality, and protein profile of strawberry fruits. J. Agric. Food Chem. 68:7246-7258.

Maeda, H., and Dudareva, N. 2012. The shikimate pathway and aromatic amino acid biosynthesis in plants. Annu. Rev. Plant Biol. 63:73-105.

Marra, R., Ambrosino, P., Carbone, V., Vinale, F., Woo, S. L., Ruocco, M., Ciliento, R., Lanzuise, S., Ferraioli, S., Soriente, I., Gigante, S., Turrà, D., Fogliano, V., Scala, F., and Lorito, M. 2006. Study of the three-way interaction between Trichoderma atroviride, plant and fungal pathogens by using a proteomic approach. Curr. Genet. 50:307-321.

Meena, M., and Swapnil, P. 2019. Regulation of WRKY genes in plant defence with beneficial fungus Trichoderma: Current perspectives and future prospects. Arch. Phytopathol. Plant Prot. 52:1-17.

Mendoza-Mendoza, A., Zaid, R., Lawry, R., Hermosa, R., Monte, E., Horwitz, B. A., and Mukherjee, P. K. 2018. Molecular dialogues between Trichoder$m a$ and roots: Role of the fungal secretome. Fungal Biol. Rev. 32:62-85.

Morán-Diez, M. E., Cardoza, R. E., Gutiérrez, S., Monte, E., and Hermosa, R. 2010. TvDim1 of Trichoderma virens is involved in redox-processes and confers resistance to oxidative stresses. Curr. Genet. 56:63-73.

Morán-Diez, M. E., Trushina, N., Lamdan, N. L., Rosenfelder, L., Mukherjee, P. K., Kenerley, C. M., and Horwitz, B. A. 2015. Hostspecific transcriptomic pattern of Trichoderma virens during interaction with maize or tomato roots. BMC Genomics 16:8.

Murashige, T., and Skoog, F. 1962. A revised medium for rapid growth and bio assays with tobacco tissue cultures. Physiol. Plant. 15:473-497.

Narula, N., Kothe, E., and Behl, R. K. 2009. Role of root exudates in plant-microbe interactions. J. Appl. Bot. Food Qual. 82:122-130.

Nieto-Jacobo, M. F., Steyaert, J. M., Salazar-Badillo, F. B., Nguyen, D. V., Rostás, M., Braithwaite, M., De Souza, J. T., Jimenez-Bremont, J. F., Ohkura, M., Stewart, A., and Mendoza-Mendoza, A. 2017. Environmental growth conditions of Trichoderma spp. affects indole acetic acid derivatives, volatile organic compounds, and plant growth promotion. Front. Plant Sci. 8:102.

Nogueira-Lopez, G., Greenwood, D. R., Middleditch, M., Winefield, C., Eaton, C., Steyaert, J. M., and Mendoza-Mendoza, A. 2018. The apoplastic secretome of Trichoderma virens during interaction with maize roots shows an inhibition of plant defence and scavenging oxidative stress secreted proteins. Front. Plant Sci. 9:409.

Oberg, A. L., and Mahoney, D. W. 2012. Statistical methods for quantitative mass spectrometry proteomic experiments with labeling. BMC Bioinf. 13:S7.

Rashti, M. R., Wang, W. J., Chen, C. R., Reeves, S. H., and Scheer, C. 2017. Assessment of $\mathrm{N}_{2} \mathrm{O}$ emissions from a fertilised vegetable cropping soil under different plant residue management strategies using ${ }^{15} \mathrm{~N}$ tracing techniques. Sci. Total Environ. 598:479-487.

Rivas-San Vicente, M., and Plasencia, J. 2011. Salicylic acid beyond defence: Its role in plant growth and development. J. Exp. Bot. 62:3321-3338.

Rodriguez, A., Kildegaard, K. R., Li, M., Borodina, I., and Nielsen, J. 2015. Establishment of a yeast platform strain for production of p-coumaric acid through metabolic engineering of aromatic amino acid biosynthesis. Metab. Eng. 31:181-188.

Rubio, M. B., Domínguez, S., Monte, E., and Hermosa, R. 2012. Comparative study of Trichoderma gene expression in interactions with tomato plants using high-density oligonucleotide microarrays. Microbiol. Read. 158:119-128.

Salas-Marina, M. A., Isordia-Jasso, M. I., Islas-Osuna, M. A., Delgado-Sánchez, P., Jiménez-Bremont, J. F., Rodríguez-Kessler, M., Rosales-Saavedra, M. T., Herrera-Estrella, A., and Casas-Flores, S. 2015. The Epl1 and Sm1 proteins from Trichoderma atroviride and Trichoderma virens differentially modulate systemic disease resistance against different life style pathogens in Solanum lycopersicum. Front. Plant Sci. 6:77.

Sayyed, R. Z., Reddy, M. S., and Antonius, S., eds. 2019. Plant Growth Promoting Rhizobacteria (PGPR): Prospects for Sustainable Agriculture. Springer, Singapore.

Sharma, S., Kour, D., Rana, K. L., Dhiman, A., Thakur, S., Thakur, P., Thakur, S., Thakur, N., Sudheer, S., Yadav, N., Yadav, A. N., Rastegari, A. A., and Singh, K. 2019. Trichoderma: Biodiversity, ecological significances, and industrial applications. Pages 85-120 in: Recent Advancement in White Biotechnology Through Fungi. Fungal Biology. A. Yadav, S. Mishra, S. Singh, and A. Gupta, eds. Springer, Cham, Switzerland.

Singh, V., Upadhyay, R. S., Sarma, B. K., and Singh, H. B. 2016. Seed biopriming with Trichoderma asperellum effectively modulate plant growth promotion in pea. Int. J. Agric. Environ. Biotechnol. 9:361-365.

Spaepen, S. 2015. Plant hormones produced by microbes. Pages 247-256 in: Principles of Plant-Microbe Interactions. B. Lugtenberg, ed. Springer, Cham, Switzerland.

Suzuki, A. 2009. Propagation strategy of ammonia fungi. Mycoscience 50:39-51.

Tohge, T., Watanabe, M., Hoefgen, R., and Fernie, A. R. 2013. Shikimate and phenylalanine biosynthesis in the green lineage. Front. Plant Sci. 4:62.

Tzin, V., and Galili, G. 2010. New insights into the shikimate and aromatic amino acids biosynthesis pathways in plants. Mol. Plant 3:956-972.

Vejan, P., Abdullah, R., Khadiran, T., Ismail, S., and Nasrulhaq Boyce, A. 2016. Role of plant growth promoting rhizobacteria in agricultural sustainability-A review. Molecules 21:573.

Verma, A., Singh, H., Anwar, M. S., Kumar, S., Ansari, M. W., and Agrawal, S. 2016. Production of thermostable organic solvent tolerant keratinolytic protease from Thermoactinomyces sp. RM4: IAA production and plant growth promotion. Front. Microbiol. 7:1189.

Viterbo, A., Landau, U., Kim, S., Chernin, L., and Chet, I. 2010. Characterization of ACC deaminase from the biocontrol and plant growthpromoting agent Trichoderma asperellum T203. FEMS Microbiol. Lett. 305:42-48.

Weisser, H., Nahnsen, S., Grossmann, J., Nilse, L., Quandt, A., Brauer, H., Sturm, M., Kenar, E., Kohlbacher, O., Aebersold, R., and Malmström, L. 2013. An automated pipeline for high-throughput label-free quantitative proteomics. J. Proteome Res. 12:1628-1644.

Wingfield, P. 2016. Protein precipitation using ammonium sulfate. Curr. Protoc. Protein Sci. 84:A.3F.1-A.3F.9.

Xie, C., Mao, X., Huang, J., Ding, Y., Wu, J., Dong, S., Kong, L., Gao, G., Li, C. Y., and Wei, L. 2011. KOBAS 2.0: A web server for annotation and identification of enriched pathways and diseases. Nucleic Acids Res. 39:W316-W322. 